\title{
LA EXTENSIÓN DEL ACUERDO DE ARBITRAJE A TERCEROS APARENTES EN EL ARBITRAJE COMERCIAL INTERNACIONAL: ANÁLISIS DE ALGUNAS TEORÍAS*
}

\section{Juan Pablo Labbé Arocca**}

RESUMEN: El acuerdo de arbitraje, por regla general, está informado por el principio del efecto relativo de los contratos. Por ello, la jurisdicción del árbitro solo alcance a quienes han manifestado su voluntad expresa de ser parte del acuerdo. Sin embargo, la práctica del comercio internacional da cuenta de una serie de situaciones en que la aplicación estricta de dicho principio no se condice con la realidad y se vuelve necesario revisar el alcance subjetivo del acuerdo. El presente trabajo busca analizar algunas de las figuras en las que la doctrina y la jurisprudencia han encontrado sustento jurídico para entender como parte en el arbitraje, a quienes aparecen como terceros en la relación contractual.

PALABRAS CLAVE: Arbitraje; Arbitraje comercial internacional; Grupo de sociedades; Levantamiento del velo corporativo; Actos propios.

\section{THE EXTENSION OF ARBITRATION AGREEMENT TO APPARENT THIRD PARTIES IN INTERNATIONAL COMMERCIAL ARBITRATION: ANALYSIS OF SOME THEORIES}

ABSTRACT: The arbitration agreement, as a rule, is informed by the principle of privity of contract. Thus, the arbitrator's jurisdiction only reach those who have expressed an explicit desire to be part of the agreement. However, the practice of international commerce shows a number of situations in which the strict application of this principle is not consistent with reality and it becomes necessary to revise the subjective scope of the agreement. This paper analyzes some of the figures in which the doctrine and jurisprudence have found legal support to understand as a party

Fecha de recepción: 1 de abril de 2017.

Fecha de aceptación: 16 de junio de 2017.

** Abogado. Universidad de los Andes (Santiago de Chile). Profesor del Departamento de Derecho Procesal de la Universidad de los Andes. Correo electrónico: labbejuanpablo@gmail. com. 
to the arbitration, to whom appears as third parties in the contractual relationship.

KEY WORDS: Arbitration; International Commercial Arbitration; Group of societies; Corporate veil lifting; Stoppel.

SUMARIO: 1) Introducción; 2) El concepto de tercero; 3) Hipótesis de extensión en el arbitraje interno; 4) Hipótesis de extensión de los efectos del acuerdo arbitral en el arbitraje comercial internacional; (4.1.) Cuestiones previas; (4.2.) Consentimiento implicito; (4.2.1.) Teoria del Estoppel o "doctrina de los actos propios; (4.2.2.) Teoría del Grupo de Empresas; (4.3.) Prescindencia de la personalidad juridica; (4.3.1.) El levantamiento del velo corporativo; 5) Aplicación de las hipótesis de extensión en la LACI; (5.1.) Consagración del principio Kompetenz-Kompetenz; (5.2.) Un escaso formalismo en el acuerdo arbitral; 6) Bibliografía.

\section{1) INTRODUCCIÓN}

A diferencia de lo que ocurre con la justicia ordinaria, la jurisdicción arbitral nace únicamente cuando las partes de una relación jurídica expresan su voluntad de someterse al juzgamiento de un árbitro. Sin entrar a repetir la clásica discusión acerca de la naturaleza jurídica del arbitraje, "independientemente del carácter contractual o jurisdiccional que se atribuya al arbitraje como institución, la naturaleza contractual del convenio arbitral resulta incuestionable" 1 . Entendido así el arbitraje, la doctrina mayoritaria $^{2}$ sostiene que, como principio general, esta institución solo alcanzará con sus efectos a quienes sean parte, expresa y voluntariamente, de la relación contractual que la origina, esto es, el acuerdo arbitral.

1 Bernardo SAn José, Alicia (2002). Arbitraje y jurisdicción, incompatibilidad y vías de exclusión, Granada: Editorial Comares, p. 7. A mayor abundamiento, SuÁrez señala que "la raíz contractual de este mecanismo de solución de controversias es el pilar de su legitimidad, dada la inmediatez entre la voluntad del juzgado y la selección del juzgador, a la vez que su gran debilidad, en términos de su eficacia frente a terceros." SuÁrez Anzorena, C. Ignacio (2005). "Algunas notas sobre los grupos de sociedades y los alcances del acuerdo arbitral según la práctica internacional”, en Revista Internacional de Arbitraje, enero-junio, pp. 55-75, p. 57.

2 VÁsquez Palma, María Fernanda (2009). Arbitraje en Chile, análisis critico de su normativa y jurisprudencia, Santiago: LegalPublishing, 384; Romero Seguel, Alejandro y Díaz VillaLовоs, José Ignacio (2016). El arbitraje interno y comercial internacional, Segunda Edición, Santiago: Ediciones UC, p. 35; Aylwin Azócar, Patricio (2005). El Juicio Arbitral, 5a ed., Santiago: Editorial Jurídica de Chile, p.379, entre otros. 
A contrario sensu, se ha entendido que nadie puede ser arrastrado al arbitraje sin que haya manifestado libremente su voluntad de someter determinadas controversias al conocimiento de un juez árbitro. Así, se ha sostenido que instituciones como la del arbitraje forzoso -consagrado actualmente en el artículo 227 del Código Orgánico de Tribunales- en donde el juicio arbitral no nace de la voluntad de las partes sino de un mandato legal para ciertas controversias, no solo se contrapone con la naturaleza misma del arbitraje sino que conlleva una vulneración de una serie de garantías constitucionales, tales como el derecho a la libertad e igualdad ante la ley, el derecho a la tutela judicial efectiva y el derecho al juez natural ${ }^{3}$.

Sin embargo, particularmente en el ámbito de las operaciones en las que normalmente se pacta arbitraje comercial internacional, como indican Merino y Chillón, "es cada vez más frecuente la presencia de contratos superpuestos, dentro de un complejo de carácter vertical y horizontal, que vinculan a diferentes personas a través de diferentes contratos conectados de alguna manera" ${ }^{4}$. En este entramado de relaciones contractuales, puede que no todas las entidades que lo conforman concurran formalmente a un acuerdo arbitral que, en realidad, está pensado para cubrir la relación jurídica completa. Así, con el fin de hacer primar la realidad material por sobre un examen meramente formalista, puede surgir la necesidad de hacer extensivos los efectos de un acuerdo arbitral a quien no ha sido formalmente parte en el mismo.

Así, ante la decisión de incluir a un tercero que no ha firmado el acuerdo de arbitraje en el juicio, el árbitro se ve enfrentado a lo que PARK ha identificado como "una tensión entre dos principios: mantener la naturaleza consensual del arbitraje, y maximizar la efectividad práctica del laudo mediante la inclusión de personas relacionadas al litigio"5. Así, aparecen contrapuestos el elemento esencialmente voluntario del arbitraje, que implica la imposibilidad de obligar a una persona a litigar en sede arbitral, con el objetivo de evitar sentencias contradictorias o ineficaces.

3 El tema es abordado en detalle en Jequier Lehuedé, Eduardo (2011), "El arbitraje forzoso. Un examen de constitucionalidad en el ordenamiento jurídico chileno", en Revista de Estudios Constitucionales, Año 9, N², pp. 453-498.

4 Merino Merchán, José y Chillón Medina, José (2014). Tratado de Derecho Arbitral, $4^{\circ}$ edición, Pamplona: Editorial Aranzadi, p. 1338.

5 PARK, William (2009). "Non-Signatories and international contracts: an arbitrator's dilemma”, en Permanent Court of Arbitration (Ed.), Multiple party actions in International Arbitration, Oxford, disponible en http://www.arbitration-icca.org/media/0/12571271340940/ park_joining_non-signatories.pdf [fecha de visita: 26 de junio de 2012]. p. 3. La traducción es nuestra, el texto original señala “... a tension between two principles: maintaining arbitration's consensual nature, and maximizing an award's practical effectiveness by binding related persons." 
Esta contraposición obliga a examinar cuidadosamente los elementos fácticos y jurídicos de cada caso, con el fin de determinar qué principio debe primar. Una opción a la ligera, en uno u otro sentido, puede llevar a desnaturalizar la institución del arbitraje, haciéndola ineficaz.

La pregunta acerca de la posibilidad de hacer extensivos los efectos de un acuerdo arbitral a un tercero se vuelve particularmente relevante a la hora de revisar la efectividad del laudo. Entendemos que, al igual que en el caso de la infracción a una hipótesis de litisconsorcio necesario, una sentencia dictada sin la comparecencia de todas las partes de la relación jurídica que da lugar al conflicto que ella resuelve, puede no ser plenamente eficaz desde el punto de vista práctico. En este sentido, se ha sostenido que "la extensión de la cláusula arbitral se vuelve, entonces, el remedio necesario para paliar los inconvenientes que puede acarrear la incorrecta delimitación del ámbito subjetivo del contrato arbitral, en la medida que su utilización despejará toda duda sobre la exactitud del mismo. Asimismo, permitiría que no se dicten sentencias contradictorias al acudirse a diferentes vías para discernir sobre los mismos hechos"6.

Este tema ha sido tratado principalmente por la doctrina comparada, donde se han propuesto una serie de figuras que permitirían configurar una excepción a la regla del efecto relativo del acuerdo arbitral, es decir, ciertas situaciones en que se justificaría la extensión a terceros de un acuerdo arbitral. El objetivo del presente trabajo es presentar el estado de la cuestión en nuestro medio y ofrecer un estudio de algunas de estas figuras $^{7}$ con el fin de analizar su posible aplicación en el derecho chileno.

\section{2) TERCEROS REALES Y TERCEROS APARENTES}

En general, al aproximarse a este tema, muchos autores señalan que en realidad a quienes se hacen extensivos los efectos del contrato de compromiso o cláusula compromisoria, no son realmente terceros, ya que quienes realmente son terceros en una relación jurídica nunca podrían

\footnotetext{
VÁsQUEZ (2009) 393.

Entre las teorías o figuras jurídicas que se han empleado para extender los efectos de un acuerdo arbitral a terceros, podemos encontrar la doctrina de los actos propios; la teoría de los grupos empresariales; la incorporación por referencia; la estipulación en favor de otro; ciertas garantías; la representación o agencia; el levantamiento del velo corporativo o alter ego; las cadenas contractuales; entre otras. Sin embargo, atendida la extensión y naturaleza del presente trabajo, solo se analizará un número reducido de estas figuras, quedando el resto de ellas para un trabajo posterior.
} 
verse afectados por los efectos del contrato ${ }^{8}$. Dicha afirmación se sustenta, a nuestro entender, en la distinción entre una dimensión sustantivo-material, referida a la relación jurídica o comercial que opera en la realidad, y una dimensión formal del acuerdo, que comprende básicamente el espectro subjetivo delimitado expresamente en el instrumento que sirve de fundamento a la relación jurídica o, en palabras más simples, las partes que comparecen formalmente al contrato.

Por lo anterior, lo que se busca no es realmente atraer al arbitraje a personas o entidades que son absolutamente ajenas a la relación contractual; sino de revelar la calidad de parte en quienes aparecen como terceros desde la óptica formal del contrato, por no comparecer al acuerdo arbitral mediante la suscripción del mismo, pero que deben ser alcanzados por los efectos del mismo en virtud de su vinculación material en la relación sustantiva que es objeto del arbitraje.

Así, la doctrina distingue entre quienes son realmente terceros y quienes solo son terceros en apariencia ${ }^{9}$. Respecto de los primeros, esto es, aquellos que no tienen ninguna vinculación material con la relación jurídica a que está referido el acuerdo arbitral, los efectos del acuerdo arbitral nunca podrán afectarlos en cuanto a su inclusión en el juicio arbitral, es decir, no podrán ser incorporados nunca como partes. Sin embargo, en determinadas hipótesis podrían verse afectados de un modo indirecto o reflejo por el laudo pronunciado en dicho procedimiento. Este último, es el supuesto en que se pone el art. 635 de nuestro actual Código de Procedimiento Civil, al disponer en su inciso tercero que "...cuando el cumplimiento de la resolución arbitral exija procedimientos de apremio o el empleo de otras medidas compulsivas, o cuando haya de afectar a terceros que no sean parte en el compromiso, deberá ocurrirse a la justicia ordinaria para la ejecución de lo resuelto". Al respecto, AYLwin señala que esta regla pareciera ir en contra del principio según el cual la competencia del árbitro estaría limitada a las personas que lo han constituido ${ }^{10}$, pero que, sin embargo, lo que realmente hace el legislador aquí es -al igual que con el resto de las sentencias judiciales- reconocer la posibilidad de afectar a terceros "no ya en cuanto declare derechos en su favor u obligaciones en su contra o los fuerce a una prestación, como les ocurre a las partes, sino en cuanto al colocar a toda persona en la necesidad de reconocer que en-

\footnotetext{
8 Graham, James (2008). "La 'falsa' extensión del acuerdo arbitral a terceros: El ejemplo de México” en Revista Peruana de Arbitraje, No 7, pp. 173-187, p. 173; VÁsquez (2009)384; PARK (2009) 1-3.

9 VÁSQUEZ (2009)384-385.

10 AylWin Azócar (2005) 378.
} 
tre las partes se ha fallado tal o cual cosa, puede implícitamente producir efectos respecto de terceros" 11 .

Los segundos, en cambio, no son realmente terceros, sino que son verdaderas partes en el arbitraje a pesar de no constar su consentimiento de un modo formal en el acuerdo arbitral, en virtud de la relación sustantiva que tienen con el objeto del arbitraje. Estos sujetos han recibido diversas denominaciones en la doctrina nacional y comparada. LARREA los ha denominado "partes sucesivas" (en contraposición a las "partes originarias"), y las define como "aquellas que, siendo terceros en la relación procesal nacida como consecuencia de la demanda, no lo son en la relación sustancial que se encuentra litigiosa y que, por tal razón, tienen la posibilidad de convertirse en 'partes', voluntaria o forzosamente en algún momento de la vida del proceso" 12 .

Por otro lado, VÁsQuez habla de "terceros aparentes" y señala que "si se revisa el convenio se verá que estos no están incluidos en él de manera expresa, pero si se indaga un poco más se llegará a la inevitable solución de que son partes de aquel, en otras palabras, en este [...] caso no se trata de terceros, sino de auténticas partes"13. Una aproximación similar propone PARK, quien habla de "less-than-obvious" parties" (partes "menos que obvias" o "no tan obvias"), partiendo de la base de que la calidad de parte en el acuerdo arbitral no se adquiere únicamente mediante la firma del mismo. En efecto, quienes comparecen formalmente en la celebración del contrato, siguiendo la nomenclatura referida, serían las partes más obvias.

11 Aylwin Azócar (2005) 382. Consideramos que se refiere aquí a lo que la doctrina ha denominado como los "efectos reflejos" de la sentencia judicial, los cuales se generan para los terceros en la relación litigiosa. Esto es posible, como señala Rosende, cuando se entiende a la sentencia como un "hecho jurídico" del cual se generan, por su sola existencia, determinados efectos no queridos ni previstos por el juez al resolver, ni perseguidos por las partes directamente al promover el proceso. Rosende Villar, Cecilia (2002). La Eficacia Frente a Terceros de las Sentencias Contencioso-Administrativas, Navarra: Aranzadi, p. 26. Por su parte, Carnelutti agrega que la noción de "eficiencia refleja" no es algo exclusivo de las decisiones jurisdiccionales, sino que es una propiedad de todos los hechos jurídicos. En este sentido, es aplicable también a los efectos del contrato -o el negocio jurídico- cuando existen determinadas relaciones de interdependencia. Carnelutti, Francisco (1944). Sistema de Derecho Procesal Civil. I introdcción y función del proceso civil, Buenos Aires: Uteha Argentina, 343346.

12 Larrea A., Ana María (2010). "Comparecencia de Terceros en un Proceso Arbitral”, en Revista Juridica. Facultad de Jurisprudencia y ciencias sociales y politicas de la Universidad Católica de Santiago de Guayaquil, vol. 28, pp. 35-47, p. 37.

13 VÁsQuez (2009) 385.

14 PARK (2009) 2-3. Más adelante el autor da una explicación acerca de quiénes serían estas "partes no tan obvias" en los siguientes términos: "individuals and entities that never put pen to paper, but still should be part of the arbitration under the circumstances of the relevant business relationship". PARK (2009) 6. 
Estas dos últimas propuestas tienen dos elementos en común que las diferencian de la primera y pueden resultar útiles para el tema en estudio: i) el término "parte" no está tomado en su sentido estrictamente procesal, el cual se adquiere con total independencia de la relación de derecho sustantivo que sirve de sustrato a un litigo, por el solo hecho de demandar o ser demandado; sino que está referido precisamente a la relación sustantiva. Esta distinción es importante porque es esta idea de "parte" a la que nos referiremos a lo largo del presente ensayo; y ii) ambas distinguen un plano aparente, determinado por la no comparecencia formal del "tercero" en el acuerdo arbitral; y un plano real -donde el tercero es, en realidad, parte del acuerdo- que debe ser desentrańado de la relación sustantiva.

\section{3) HIPÓTESIS DE EXTENSIÓN EN EL ARBITRAJE INTERNO}

En el ámbito del arbitraje interno, la aplicación del principio del efecto relativo del acuerdo arbitral es más estricta. En este sentido, según nuestra doctrina nacional, salvo acotadas excepciones referidas a hipótesis de obligaciones solidarias ${ }^{15}$, sucesión procesal -o cambio de partes- y subrogación legal ${ }^{16}$, no sería posible extender los efectos del compromiso o cláusula compromisoria a terceros que no han sido partes de dicho acuerdo en sentido formal.

En opinión Romero, esta limitación estaría dada principalmente por la forma de instalación del tribunal arbitral. En efecto, una vez asumido el cargo, el árbitro debe citar a las partes a un primer comparendo para fijar las reglas del procedimiento, lo cual se cumple de manera estricta tanto en el arbitraje ad hoc como en el institucional. En esta audiencia, el

15 En efecto, se ha dicho que "cuando hay solidaridad entre acreedores o entre deudores, el compromiso celebrado entre uno de los acreedores con el deudor o entre uno de los deudores con el acreedor respecto del crédito u obligación solidaria, afecta a todos los demás acreedores, o a todos los demás deudores, respectivamente". AylWin Azócar (2005) 296.

16 Romero/Díaz (2016) 36-38; Romero Seguel, Alejandro (2011). Curso de Derecho Procesal Civil, tomo III, Santiago: Editorial Jurídica de Chile, pp. 26-30. En los casos descritos, entendemos que más que una genuina extensión de los efectos del acuerdo arbitral, más bien existe una transferencia del mismo. La diferencia no es menor, puesto que estos casos normalmente deben ser resueltos a partir de la aplicación del derecho sustantivo que rige el fondo del asunto, mientras que la extensión propiamente tal responde a la aplicación de principios que podrían no estar recogidos en la ley del fondo, tales como el kompetenz-kompetenz o el de autonomía de la cláusula arbitral. Una explicación de esta distinción puede encontrarse en Díaz-Candia, Hernando, (2012) "Extensión intersubjetiva del acuerdo de arbitraje de Estado" en Soto Coaguila, Carlos Alberto (Dir.) Aplicación del convenio arbitral a partes no signatarias. Intervención de terceros en el arbitraje, Lima: Instituto Peruano de Arbitraje, pp. 161-174, pp. 164-165. 
árbitro deberá determinar quiénes son los sujetos vinculados expresamente por el acuerdo arbitral, según conste su manifestación de voluntad en el contrato de compromiso o cláusula compromisoria ${ }^{17}$. Es más, el mismo autor sostiene que "el árbitro ad hoc o el centro de arbitraje institucional podría ser sujeto pasivo de una acción constitucional de protección si no respeta el ámbito subjetivo del acuerdo arbitral. La base de lo anterior está en el artículo $19 \mathrm{~N}^{\circ} 3$ inc. 4 de la Constitución, al disponer que 'nadie puede ser juzgado por comisiones especiales, sino por el tribunal que le señalare la ley y que se hallare establecido con anterioridad a la perpetración del hecho" 18 .

Sin embargo, el referido impedimento no es, al menos absoluto en nuestra jurisprudencia en materia de arbitraje interno. Así, por ejemplo, por sentencia de la Corte Suprema de 2 de junio de $2009^{19}$ se extendieron los efectos de la cláusula compromisoria, aplicando una de las hipótesis que se estudiarán más adelante: el levantamiento del velo corporati$v^{20}$. Los hechos se remontan al ańo 1999, cuando la sociedad Tripseca S.A. (empresa pesquera) celebró un contrato de remolque-transporte con la empresa Ultragas Agencia Marítima Limitada (en adelante Ultragas), para trasladar por mar un muelle flotante recién construido desde Puerto Montt hasta la planta de Tripseca S.A. en Corral. El día 5 de septiembre de dicho año la empresa que construyó el muelle se lo entregó al representante de la sociedad Ultramar Agencia Marítima Limitada (en adelante Ultramar). Al día siguiente, mientras el muelle era transportado se ladeó y se hundió, debiendo A.G.F. Allianz Compañía de Seguros Generales S.A. (en adelante Aseguradora) reembolsar a Tripseca S.A. la suma correspondiente al contrato de seguro. Habiéndole subrogado en todos los derechos y obligaciones contra terceros, la aseguradora procedió a interponer una demanda ordinaria de indemnización de perjuicios en contra de Ultramar y Ultragas ante el Juez Árbitro don Juan Pablo Monti Medina. La contraparte opuso excepción de inoponibilidad, basándose en que el contrato de remolque-transporte habría sido celebrado por Tripseca S.A. y Remolcadores Ultragas Limitada, siendo esta una persona jurídica distinta e in-

17 Romero Seguel, Alejandro (2012). "La extensión del convenio arbitral a partes no signatarias: límites y posibilidades en Chile” en Soтo Coaguila, Carlos Alberto (Dir.) Aplicación del convenio arbitral a partes no signatarias. Intervención de terceros en el arbitraje, Lima: Instituto Peruano de Arbitraje, pp. 3-14, pp. 4-6.

18 Romero/Díaz (2016) 40-41

19 Corte Suprema, 2 de junio de 2009, Causa Rol No 1527-2008, disponible en Microjuris. com, código MJJ20190, consultada por última vez el 27 de julio de 2014.

20 Un comentario de esta sentencia, con énfasis en el reconocimiento que hace la Corte de la doctrina del levantamiento del velo corporativo, en Urbina Molfino, Ignacio (2011). "Levantamiento del Velo Corporativo. Sentencia de la Corte Suprema de 2 de junio de 2009". Revista Chilena de Derecho, Vol. 38 No 1, pp. 163-171. 
dependiente de Ultragas y Ultramar. Sin embargo, tanto el Juez Árbitro, como la Corte de Apelaciones y la Corte Suprema, aplicando la doctrina del levantamiento del velo societario, dieron lugar a la demanda en contra de todas las demandadas entendiendo que, en realidad, existía una unidad económica entre las distintas sociedades.

\section{4) Hipótesis de eXtensión de los efectos del ACUERdo ARBITRAL EN EL ARBITRAJE COMERCIAL INTERNACIONAL}

\section{(4.1.) CUESTIONES PREVIAS}

Como se anticipó, en el comercio internacional se han generado relaciones contractuales cada vez más complejas, las cuales exigen, en ocasiones, atenuar el efecto relativo de los contratos para hacer extensivos los efectos de los acuerdos arbitrales a terceros no signatarios, transformándose este en uno de los tópicos más relevantes en la práctica del arbitraje comercial internacional ${ }^{21}$.

Así, la doctrina nacional y comparada ha encontrado una justificación para la extensión del arbitraje en una serie de instituciones jurídicas que, de un modo u otro, revelan la verdadera posición que ocupan ciertos "terceros" -que en realidad no son tales sino en apariencia- en un arbitraje comercial internacional. Tales instituciones han sido sistematizadas en distintos modos por la doctrina. Así, algunos las dividen entre aquellas que enfatizan el consentimiento del no signatario y aquellas en las que la extensión se da por fuerza de la ley ${ }^{22}$. Para otros, según explica MeremINSKAYA, "el elemento central de todas esas teorías radica precisamente en el consentimiento y la intención genuina de todos los contratantes a considerar a una persona no signataria del acuerdo arbitral como parte del mismo" 23 . Sin embargo, en nuestra opinión existen figuras que no responden necesariamente a dicho consentimiento, como es el caso del levantamiento del velo corporativo, donde la intención del no signatario, al instrumentalizar distinción entre personalidades jurídicas, puede ser precisamente no ser alcanzado por la cláusula arbitral suscrita por su filial.

21 Aguilar Grieder, Hilda (2001). La extensión de la cláusula arbitral a los componentes de un grupo de sociedades en el arbitraje comercial internacional, Santiago de Compostela: Universidad de Santiago de Compostela, p. 35.

22 Mereminskaya, Elina (2012). "Aplicación de un acuerdo arbitral a un tercero no signatario en el derecho chileno: Realidad y perspectivas" en Estudios de Derecho Comercial. III Jornadas chilenas de Derecho Comercial, Facultad de Derecho Universidad de Chile, pp. 347-355, p. 348 .

23 MereminsKaya, Elina (2012) 348 
En este sentido, Park indica que "la mayoría de las explicaciones para la extensión se refiere a (1) el consentimiento implícito o (2) hacer caso omiso de la personalidad corporativa. En cualquier caso, un acuerdo de arbitraje debe existir. Sin embargo, los efectos del acuerdo van más allá de las partes firmantes, en virtud de una conducta que, o bien sugiere la aceptación del acuerdo por parte de otra persona o justifica ir más allá de la forma corporativa de la entidad firmante" 24 . Intentaremos clasificar dentro de estos dos grupos algunas de las diversas instituciones con las que se ha intentado explicar la figura en estudio.

\section{(4.2.) CONSENTIMIENTO IMPLÍCITO}

Tal como se desprende del análisis realizado al concepto de "tercero", no existe una identificación necesaria entre quienes comparecen formalmente al acuerdo arbitral mediante la firma del mismo, y quienes deben ocupar la posición de parte en el juicio arbitral. En efecto, "no parece que las leyes nacionales ni tampoco las normas internacionales condicionen de forma definitiva la posibilidad de que el consentimiento de una empresa a someter sus controversias a arbitraje deba de constar ineludiblemente por escrito o mediante aceptación del envío del documento que contiene el acuerdo arbitral. Este consentimiento respecto de la cláusula arbitral escrita puede derivarse de forma implícita de actos o hechos distintos a la forma del convenio arbitral como manifestación expresa de su aceptación" 25 .

Sin embargo, también hay que recordar que el "elemento más relevante del arbitraje es el valor que se reconoce a la autonomía de la voluntad, como quicio de todo el sistema arbitral" 26 , de modo que el consentimiento constituye la piedra angular del $\mathrm{mismo}^{27}$. Esta realidad ha de tenerse en cuenta a la hora de extender los efectos de una cláusula arbitral

24 PARK (2009) 3. La traducción es nuestra, el texto original señala: "However, most explanations of joinder relate to either (1) implied consent or (2) disregard of corporate personality. In each case, an agreement to arbitrate must exist. However, the effect of that agreement extends beyond the named signatories, by virtue of behavior that either suggests acceptance of the agreement by someone else or justifies going beyond the corporate form of the signatory entity".

25 De Nadal, Elisabeth y Sánchez, Víctor Manuel (2011). "La extensión a terceros no firmantes de los efectos del convenio arbitral. La aproximación de España” en Soto CoAguiLA, Carlos Alberto (Dir.), Tratado de Derecho Arbitral. El Convenio Arbitral, Bogotá: Grupo Editorial Ibáñez, T. I, pp. 689-704, p. 690. Hay que decir, sin embargo, que esta afirmación se hace en referencia a la legislación española, pero es transcrita con el fin de introducir al tema.

26 Romero/Díaz (2016) 2.

27 PARK (2009) 2. 
a personas o entidades que no han manifestado su consentimiento de manera expresa. Por lo anterior, el consentimiento implícito ha de buscarse en hechos reales y objetivos que den cuenta de la voluntad de participar en el arbitraje.

En este sentido, las teorías de consentimiento implícito encuentran un suficiente margen de aplicación en nuestra legislación interna. La LACI, "siguiendo la Ley Modelo de CNUDMI, reconoce un acuerdo de arbitraje si la controversia existente o futura se refiere a una 'determinada relación juridica contractual o no contractual', dándosele a esta expresión una interpretación amplia, de modo que abarque todos los asuntos comerciales no contractuales que ocurran en la práctica" ${ }^{28}$. En palabras de FigueroA, lo anterior permitiría reconocer, entre otras cosas, la intervención de un tercero en la relación contractual ${ }^{29}$.

A lo anterior hay que sumar la poca formalización que prevé la ley para el convenio arbitral, estableciendo como única exigencia la forma escrita del mismo, lo cual facilitaría la eventual extensión a terceros del acuerdo $^{30}$. Esto se ha hecho concreto en otros países que han adoptado la ley modelo UNCITRAL en donde algunas cortes, en virtud de lo dispuesto en ella, han permitido que la jurisdicción arbitral se desprenda de un contrato no firmado, como una orden de compra ${ }^{31}$.

De lo anterior podemos concluir que nuestra regulación en materia de arbitraje comercial internacional está informada por un principio de flexibilidad e informalidad en lo relativo a la formación del consentimiento en el acuerdo arbitral. Este es el punto de partida para analizar cada una de las teorías de consentimiento implícito que permitirían extender los efectos del arbitraje a terceros, las cuales no encontrarían cabida en nuestro medio si no fuera por la existencia de dicho principio.

\section{(4.2.1.) Teoría del Estoppel o "doctrina de los actos propios"}

La doctrina de los actos propios -formulada comúnmente mediante el adagio Venire contra factum propium non valet, proveniente del derecho romano ${ }^{32}$ - puede definirse en términos simples como una "regla de derecho, derivada del principio general de la buena fe, que sanciona como in-

28 Figueroa Valdés, Juan Eduardo (2007). “Tópicos de la Ley No 19.971, sobre arbitraje comercial internacional”, en Picand Albónico, Eduardo (coord.), Estudios de Arbitraje, Santiago: Editorial Jurídica de Chile, pp. 391-409, p. 401.

29 Figueroa (2007) 401.

Romero (2012) 7.

PARK (2009) 7.

Sobre las raíces históricas de dicha formulación. Corral Talciani, Hernán (2010). "La raíz histórica del adagio 'venire contra factum propium non valet', en Corral Talciani, Hernán 
admisible toda pretensión lícita pero objetivamente contradictoria respecto del propio comportamiento anterior efectuado por el mismo sujeto"33. Por su parte, la doctrina del estoppel -de marcado arraigo en el derecho anglosajón ${ }^{34}$ - implica que "una persona, por medio de una presunción iure et de iure (que no admite prueba en contrario), queda impedida de rebatir dentro del proceso aquellos hechos que son derivaciones inmediatas de sus declaraciones o bien de sus actos (pues la persona puede quedar también vinculada a los hechos que implícitamente ha establecido, no ya con sus palabras, sino a través de sus propias conductas)" 35 . Es posible constatar una clara similitud entre ambos $\operatorname{conceptos}^{36}$, por lo cual nos referiremos a ellos indistintamente para los efectos de demostrar cómo su aplicación puede ser útil a la hora de extender los efectos del acuerdo arbitral a una parte que no ha comparecido al mismo.

Como señala Borda, esta teoría descansa sobre tres presupuestos básicos. El primero consiste en que un sujeto realice una conducta que sea jurídicamente relevante y eficaz, y que suscite la confianza de un tercero. En segundo lugar, es necesaria una posterior pretensión, judicial o extrajudicial, que, siendo lícita en sí misma, sea objetivamente contradictoria con la conducta anterior. Finalmente, es preciso que los sujetos intervinientes en ambas conductas sean los mismos o que, al menos, el centro de interés sea el mismo ${ }^{37}$. Aguilar destaca de esta explicación que

(edit.), Venire contra factum propium, Cuadernos de Extensión Jurídica No 18, Santiago: Universidad de los Andes, pp. 19-33.

33 Borda, Alejandro (2010). "La teoría de los actos propios. Un análisis desde la doctrina argentina", en Corral Talciani, Hernán (edit.), Venire contra factum propium, Cuadernos de Extensión Jurídica No 18, Santiago: Universidad de los Andes, pp. 35-55, p. 35.

34 Bernal-Fandiño, Mariana y Rojas-Quiñones, Sergio (2010). "La vinculatoriedad de un laudo arbitral frente a terceros en la doctrina del collateral estoppel'. Revista Colombiana de Derecho Internacional, $\mathrm{n}^{\circ} 16$, pp. 455-488, p. 458.

35 Ekdahl Escobar, María Fernanda (1989). La doctrina de los actos propios, Santiago: Editorial Jurídica de Chile, p. 76.

36 La diferencia entre uno y otro concepto estaría dada principalmente por razones históricoculturales. En efecto, la doctrina del estoppel ha nacido y se ha desarrollado en el derecho anglosajón; mientras que la teoría de los actos propios es propia del derecho latino-continental. En este sentido, como reconoce EKDAHL, "si bien se trata de técnicas que responden al mismo programa de intereses protegidos, no nacen ni aparecen en forma coetánea, ni se les brinda posteriormente el mismo tratamiento. [...] estoppel y la regla que impide ir contra los propios actos se encuentran en estadios de evolución diferentes. La primera ha sido elaborada en forma más amplia, por lo que el concepto es más lato, pudiendo ser aplicado a mayor cantidad de supuestos". Ekdahl (1989) 80. Tanto así, que el estoppel tiene muchas variantes, tales como el estoppel by record, el estoppel by deed, el collateral stoppel y el estoppel in pais, siendo esta última variante la que más cercanía tendría con la doctrina de los actos propios. Corral (2010) 31.

37 Borda (2010) 43-50. A estos presupuestos EKDAHL agrega la necesidad de que la contradicción genere perjuicios a terceros. En este sentido, a la defraudación de la confianza generada por la primera conducta, se agrega el perjuicio que pueda ocasionar la pretensión posterior a los terceros que, basados en dicha confianza hayan efectuado actos que hayan alterado su 
la confianza generada por la primera conducta del sujeto es precisamente lo que se busca proteger mediante esta doctrina ${ }^{38}$. En este sentido se ha sostenido que esta institución resguarda "la confianza originada en la apariencia jurídica creada por las partes en el proceso, a la par que tutela su coherencia comportamental" 39 . En efecto, hay que recordar que la doctrina del estoppel descansa sobre el principio de la buena fe ${ }^{40} \mathrm{y}$ por tanto, en cuanto a su exigibilidad, "tiene el mismo valor y el mismo alcance que el principio del cual deriva" 41 .

Para lo que aquí importa, algunos autores han opinado que "la práctica arbitral internacional ha recurrido en una buena parte de las ocasiones a la doctrina de los actos propios, [...] para justificar la ampliación subjetiva de la cláusula arbitral" 42 . Lo anterior se explica, tomando como punto de partida la descripción dada anteriormente sobre esta figura, entendiendo que en la primera conducta del agente, lo que se contiene es el consentimiento implícito de ser alcanzado por los efectos del acuerdo arbitral. Así, la doctrina de los actos propios sería útil para sacar a la luz dicho consentimiento. En efecto, "la extensión del acuerdo de arbitraje a un tercero no signatario es generalmente aceptada por la doctrina jurídica si ese tercero, en relación a la conclusión o desenvolvimiento del contrato principal, actuó de manera tal que la parte contraria, de buena fe, pudo entender que el tercero deseaba incorporarse o aceptar el contrato principal así como el acuerdo de arbitraje” 43 .

posición jurídica de alguna manera. EKDAHL (1989) pp. 115-16. Consideramos que la sola defraudación de la confianza suscitada por los propios actos es, en sí misma, una lesión a la buena fe, con independencia de los perjuicios materiales en que pudiera incurrir quien actúa en base a ella.

38 Aguilar (2001) 288.

39 Bernal-Fandiño/Rojas-Quiñones (2010) 460.

40 Aguilar (2001) 289; Romero (2012) 11; Carreta Muñoz, Francesco (2008). "Deberes procesales de las partes en el proceso civil chileno: referencia a la buena fe procesal y al deber de coherencia". Revista Chilena de Derecho (Valdivia), Vol. 21 No 1, pp. 101-127, p. 121; López Mesa, Marcelo (2009). "La doctrina de los actos propios: Esencia y requisitos de aplicación". Vniversitas, No 119 jul./dic., pp. 189-222, p. 191.; EKdaHL (1989) 59-73; Borda (2010) 39; Contardo González, Juan Ignacio (2010). "La doctrina de los actos propios en la jurisprudencia civil chilena", en Corral Talciani, Hernán (edit.), Venire contra factum propium, Cuadernos de Extensión Jurídica No 18, Santiago: Universidad de los Andes, pp. 81-102, p. 83.

41 Aguilar (2001) 289.

42 Aguilar (2001) 286. Hay que señalar, sin embargo, que al menos en cuanto a la aplicación de esta doctrina para extender los efectos de la cláusula arbitral a terceros en un grupo de sociedades, la autora discrepa con dicha opinión, señalando que "son muy pocas las sentencias que han recurrido, explícita o implícitamente, a la figura jurídica del estoppel, en cualquiera de sus modalidades, para extender la cláusula arbitral a las sociedades no suscriptoras de un grupo". Aguilar (2001) 318.

43 MüLlER, Thomas (2009). "Extension of arbitration agreements to third parties under Swiss law" en PLC Cross-border Arbitration Handbook, disponible en www.practicallaw.com/9385-8457, visitado por última vez el 11 de mayo de 2012, p.10. La traducción es nuestra, 
Avanzando un paso más, surge la cuestión acerca de qué criterios se han de utilizar para determinar que una parte no signataria realiza conductas de las cuales se desprende una voluntad de participar del contrato. Delimitar esto es importante ya que, como dijimos anteriormente, en toda esta operación de determinar el ámbito subjetivo de la relación arbitral, no puede pasarse a llevar el principio de la voluntad de las partes, que es el fundamento mismo de la jurisdicción arbitral. Así, nos parece necesario establecer un parámetro objetivo para calificar una conducta de modo tal que comporte la voluntad de ser parte en el arbitraje.

En este sentido, la jurisprudencia norteamericana ha aplicado la teoría del estoppel "en consideración de la previa conducta de la parte que resiste el arbitraje, por ejemplo, para rechazar acciones judiciales tendientes a evitar ser llevado a arbitraje, promovidas por quien ha 'explotado conscientemente el contrato' y 'aceptado sus beneficio" 44 y ha agregado como requisito que "esos beneficios deben ser directos, es decir, que deben surgir directamente del acuerdo, no alcanzando y sean meramente indirectos" ${ }^{25}$. En otras palabras, según esta doctrina, la verificación del primer requisito para aplicar la teoría del estoppel -esto es, la conducta que genera en el resto de los intervinientes la confianza de que se es parte de la relación contractual- requerirá además que el tercero obtenga beneficios directos del acuerdo.

Sin embargo, no nos parece que dicho criterio sea suficiente. Si entendemos que "el núcleo de la figura del estoppel es la 'apariencia', o mejor aún, es la confianza depositada en esa apariencia jurídica y la buena fe derivada de la confianza suscitada" 46 , hay que ir más allá de los posibles beneficios que haya aprovechado el tercero. Más bien, hay que revisar si se han dado las circunstancias objetivas suficientes para generar dicha confianza. En este sentido, siguiendo a BORDA, es necesario que la primera conducta sea jurídicamente relevante y eficaz ${ }^{47}$. Nosotros entendemos

el texto original señala: "the extension of the arbitration agreement to a non-signatory third party is generally affirmed in legal doctrine if such third party, in relation to the conclusion or performance of the main contract, acted in a way in which the opposite side, in good faith, could understand that the third party wished to join and accept the main contract as well as the arbitration agreement"

44 Caivano, Roque (2006), "Arbitraje y grupos de sociedades. Extensión de los efectos de un acuerdo arbitral a quien no ha sido signatario". Lima Arbitration. Revista del Círculo Peruano de Arbitraje, No1, pp. 121-162, p. 135.

45 CaIvano (2006) 135.

46 BORDA (2010) 40.

47 Borda (2010) 44. El autor señala que esto implica excluir todas aquellas conductas sin valor jurídico y las que requieran imperativamente una forma determinada que no fuese cumplida; así como las que no son jurídicamente vinculantes - como una mera opinión- o las que solo constituyan la manifestación de una intención. Así, lo que se requiere en realidad es que la conducta importe una toma de posición frente a una situación determinada y genere 
esa relevancia jurídica, para este caso en concreto, como la participación voluntaria en alguno de los efectos de la relación jurídica aparentemente ajena. Esto implica ampliar el margen de conductas jurídicamente relevantes más allá del mero beneficio directo -que sería participar de solo una clase de efectos, a saber, los derechos- e incluir aquellos actos que comporten el cumplimiento de alguno de los deberes del contrato. En efecto, una conducta que comporte el cumplimiento de algunos de los deberes emanados del contrato no se explicaría por sí sola a menos que se entienda que quien la realiza tiene la voluntad de participar en el mismo. En suma, consideramos que han de considerarse como conductas jurídicamente relevantes -y que generan en el resto la confianza de que se quiere participar del negocio- todas aquellas que impliquen una participación voluntaria en los efectos del contrato en cuestión, ya sea disfrutando de los derechos que este genera o cumpliendo con sus deberes.

De este modo, una vez verificada la intención de ser parte en el contrato que contiene la cláusula arbitral, por parte del tercero que realiza una conducta como la recién descrita, no sería posible, en razón de la teoría de los actos propios, que posteriormente alegue su calidad de tercero para no ser alcanzado por los efectos del arbitraje.

Por otro lado, una parte de la doctrina señala que "la ampliación subjetiva de la cláusula arbitral no debiera basarse en presuntas voluntades de las partes, sino que debiera considerarse como una 'sanción' que trae su causa de criterios menos subjetivos y aleatorios al de la voluntad de las partes tales como la apariencia, la confusión y la intromisión deliberada de una sociedad en el funcionamiento de otra" ${ }^{48}$. En un sentido similar se ha pronunciado Lyon al sostener que "lo que expresa el refrán del Venire contra factum propium non valet y la misma teoría de los actos propios es la sanción a un dolo o mala fe ostensible del agente, que aparece de la contradicción evidente y manifiesta con una conducta previa vinculante suya" ${ }^{49}$. Más allá de la función que pueda cumplir esta doctrina

la confianza en el resto respecto de dicha posición. Se propone como ejemplo aquellas conductas que dan como existente una determinada situación de hecho. En similar sentido se ha pronunciado EKDAHL señalando que "la relevancia jurídica de la conducta vinculante implica que, para que esta sea estimada por el derecho como tal, ha de poseer un carácter trascendente, fundamental, a través del cual se defina certeramente, en forma clara y precisa, la postura o actitud que el agente asume frente a una situación jurídica dada”. EKDAHL (1989) 106-107.

48 Aguilar (2001) 299.

49 Lyon Puelma, Alberto (2010). "Crítica a la doctrina del acto propio: ¿Sanción de la incoherencia o del dolo o la mala fe?” en Corral Talciani, Hernán (edit.), Venire contra factum propium, Cuadernos de Extensión Jurídica No 18, Santiago: Universidad de los Andes, pp. 59-68, p. 62. En este sentido, el autor seńala que si se excluye el elemento del dolo de la teoría del acto propio, esta implicaría exigir un nivel de coherencia a las personas que atenta 
como una sanción a la mala fe de quien realiza los actos contradictorios, lo anterior nos lleva a centrar la mirada en el fundamento mismo del estoppel, es decir: el resguardo de la buena fe.

A partir de lo anterior, la existencia de una vulneración al principio de la buena fe debe constituir un requisito sine qua non para la aplicación de la teoría de los actos propios en la extensión a terceros de los efectos del acuerdo arbitral. No solo por ser esa la base de la teoría, sino que además, porque se está ampliando el ámbito subjetivo de una relación jurídica particular -el arbitraje- que descansa radicalmente sobre la voluntad de las partes de participar de ella. Por esta razón, cualquier institución que se utilice para realizar dicha extensión debiera aplicarse de modo restringido. En este sentido, toca ahora preguntarnos cómo determinar dicha vulneración en la conducta del agente para poder hacer procedente la extensión.

Como ya dijimos anteriormente, la transgresión al principio de la buena fe se vería verificada en la defraudación ocasionada por la conducta incoherente del agente que evita someterse al juicio arbitral. En efecto, no se trata de buscar en la intencionalidad del tercero aparente una actitud dolosa, lo que sería aún más complejo al tratarse de personas jurídicas, como es en la mayoría de los casos; sino que se busca descubrir una defraudación a la confianza de quien, de buena $\mathrm{fe}^{50}$, se basó en la primera conducta para considerar a dicho tercero como parte en la relación contractual.

\section{(4.2.2.) Teoría del Grupo de Empresas}

Otra doctrina que ha sido ampliamente tratada por la literatura nacional y comparada en el presente tema, es la teoría del Grupo de Empresas o Grupo de Sociedades, que en palabras de Courtney, "es otro medio por el cual las cortes han reconocido el consentimiento implícito e incorporado a partes no signatarias en acuerdos de arbitraje" 51 . En este caso,

contra su libertad individual y no se condice con la naturaleza propia de los seres humanos. En otras palabras, significaría desconocer que es propio de los hombres que ejecuten actos o emitan opiniones en un sentido y que posteriormente cambien su parecer por diversas razones; y sancionar esta situación sería excesivo. Lyon (2010) 63.

50 En este sentido se ha pronunciado la Corte Suprema al señalar que, respecto de la aplicación de la doctrina de los actos propios, es necesario que el sentenciador preste atención no tanto a la mala fe de quien ejecuta la conducta contradictoria sino a la buena fe del sujeto pasivo de la misma. Jurisprudencia citada en Contardo (2010) 84.

51 Courtney, Tae (2009). "Binding non-signatories to international arbitration agreements: raising fundamental concerns in the United States and abroad" en Richmond Journal of Global Law \& Business, Vol. 8, issue 4, pp. 581-594, p. 588. La traducción es nuestra, el texto original señala: The group of companies doctrine is another means by which courts have 
la pregunta es si un acuerdo arbitral suscrito por una compañía vincula a las entidades integrantes del mismo grupo de empresas, a pesar de tener estas una personalidad jurídica diferente y no haber suscrito el contrato que contiene la cláusula, ya sea porque han tenido algún grado de participación en el contrato afectado por la cláusula ${ }^{52}$ o porque, en su conjunto, representan una realidad económica única o singular ${ }^{53}$.

En nuestro derecho, existen diversas regulaciones que reconocen y definen, a veces de modo directo y otras de modo indirecto, a los grupos empresariales. Así, en el ámbito del derecho laboral esta institución ha sido definida como aquella integrada "por diversos sujetos jurídicos, cada uno formalmente independiente y revestido de personalidad jurídica propia y diferenciada, pero que sin embargo actúan bajo una dirección económica común, originando una separación entre la realidad material y las formas jurídicas" ${ }^{54}$. Por otra parte, en materia de mercado de valores, la Ley $\mathrm{N}^{\circ} 18.045$ (LMV) contiene, entre sus artículos 96 a 102, una regulación precisamente referida a los grupos empresariales, los cuales define, en su artículo 96, como el conjunto de entidades que presentan vínculos de tal naturaleza en su propiedad, administración o responsabilidad crediticia, que hacen presumir que la actuación económica y financiera de sus integrantes está guiada por los intereses comunes del grupo o subordinada a estos, o que existen riesgos financieros comunes en los créditos que se les otorguen o en la adquisición de valores que emiten ${ }^{55}$.

Otra definición, dada por Jarrosson, entiende al grupo de sociedades como "un conjunto de sociedades en que cada una de ellas tiene una personalidad jurídica propia y distinta, conjunto que no tiene en tanto

recognized implied consent and bound non-signatories to arbitration agreements. Cabe señalar que, en opinión de algunos autores, esta doctrina no es más que la aplicación de una interpretación más moderna del consentimiento, no existiendo una real extensión de los efectos del acuerdo arbitral sino una determinación de las verdaderas partes del mismo, debiendo incluso eliminarse el concepto mismo de "doctrina del grupo de sociedades" Hanotiau, Bernard y Stein, Erica (2012). "La extensión de los efectos del convenio arbitral a no signatarios: ¿Una marginalización del consentimiento?” en Soto CoAguila, Carlos Alberto (Dir.) Aplicación del convenio arbitral a partes no signatarias. Intervención de terceros en el arbitraje, Lima: Instituto Peruano de Arbitraje, pp. 57-67, p. 67.

52 De NadAL/SÁNCHez (2011) 699.

53 Blackaby, Nigel y Partasides, Constantine (2015). Redfern and Hunter on International Arbitration, 6ta ed., Oxford: Oxford University Press, p. 85.

54 Aylwin Chiorrini, Andrés y Rojas Miño, Irene (2005). "Los Grupos de Empresas y sus efectos jurídico laborales en el Derecho Comparado" en Ius et Praxis, Vol. 11, No 2, pp. 197-225, p. 198.

55 En esta oportunidad no ahondaremos en la regulación de los grupos empresariales contenidos en la LMV. Sin embargo, un análisis pormenorizado de los elementos que configuran tales grupos en dicho cuerpo normativo en Jequier LeHuedé, Eduardo (2015). Grupos empresariales. Notas sobre la responsabilidad del administrador de hecho en el derecho chileno, Santiago: LegalPublishing, pp. 50 y siguientes, 
que tal personalidad jurídica, incluso si de hecho existe una unidad de decisión, de gestión o de control" 56.

A partir de estas definiciones es posible concluir que, a pesar de la independencia jurídica existente entre las distintas compańías, lo que existe realmente es una unidad económica ${ }^{57}$, dando lugar así a lo que Aguilar señala como una realidad contradictoria y dual, por un lado jurídica y por otro económica ${ }^{58}$. Desde el punto de vista jurídico, no existe una unidad indisociable ya que la existencia de diversas personas jurídicas dan cuenta de una clara pluralidad e independencia, lo que "implica, al menos a priori, [que] cada una de las sociedades del grupo no esté obligada por los compromisos asumidos por cualquiera de las restantes sociedades" 59 . Por otro lado, las relaciones de control directo o indirecto que se da entre las distintas sociedades (que generalmente son matrices y filiales) así como la dirección y estrategia común en el ámbito económico, dan cuenta de la existencia de una unidad de hecho ${ }^{60}$.

Al explicar este tema, la mayoría de los autores suelen recurrir a un caso jurisprudencial ${ }^{61}$ que resulta paradigmático en cuanto a la extensión

56 Citado en Aguilar (2001) 50-51. La autora hace referencia, allí mismo, a otra definición que nos parece pertinente reproducir. GuYon señala que "el grupo es un conjunto de sociedades jurídicamente independientes las unas de las otras pero de hecho sometidas a una unidad de decisión económica".

57 Así lo ha entendido, entre otros, Brinsmead, Simon (2007). Extending the application of an arbitration clause to third-party non-signatories: which law should apply?, working papers series, Social Science Research Network, disponible en http://ssrn.com/abstract=980483 [fecha de visita: 18 de septiembre de 2012]. Aguilar Grieder, Hilda (2009). "Arbitraje Comercial Internacional y Grupos de Sociedades" en Cuadernos de Derecho Transnacional, Vol. 1, No 2, pp. 5-29, p. 8.

59 Aguilar (2009) 9.

60 Según esta autora, esta realidad dual ha de ser especialmente considerada a la hora de plantearse la posibilidad de extender los efectos de una cláusula arbitral a compañías pertenecientes al grupo de sociedades que no hayan sido signatarias. Si, por un lado, solo se considera la realidad económica unitaria, los efectos de la cláusula tendrían que extenderse automáticamente, lo que atentaría contra la autonomía jurídica de las sociedades y contra la naturaleza consensual del arbitraje, perjudicando así la credibilidad que merece el arbitraje comercial internacional. Asimismo, si se considera únicamente la pluralidad jurídica, haciendo una interpretación estricta y formalista del convenio arbitral, se haría imposible la inclusión en el arbitraje de las compañías no signatarias del grupo, que bien podrían tener una relación sustancial con el contrato que contiene la cláusula, produciendo así un fraccionamiento del litigio. Aguilar (2009) 9.

61 Entre otros, Park (2009) 20; Caivano (2006) 125; Aguilar (2009) 14; Brinsmead (2007) 5; TANG, Edward Ho-ming (2009). Methods to extend the scope of an arbitration agreement to third party non-signatories, Run Run Shaw Library, City University of Hong Kong, disponible en http://lbms03.cityu.edu.hk/oaps/slw2009-4635-thm665.pdf [fecha de visita: 18 de septiembre de 2012]; Suárez (2005) 61; Blackaby/Partasides (2015) 86; Medina Garnes, Fabiola y Fermín Cabral, Manuel (2012). "Extensión del convenio arbitral a partes no signatarias y la intervención de terceros en el arbitraje” en Soto CoAguila, Carlos Alberto (Dir.) Aplicación del convenio arbitral a partes no signatarias. Intervención de terceros en el arbitraje, Lima: Instituto Peruano de Arbitraje, pp. 85-96, p. 92. 
de la cláusula arbitral por medio de la teoría del grupo de sociedades: Dow Chemical con Isover Saint Gobain, resuelto en 1982.

Los hechos se originan a partir de dos contratos idénticos que vinculaban a Dow Chemical $A G$ (sociedad suiza) y a Dow Chemical Europe con el grupo multinacional francés Isover Saint Gobain, para la distribución en Francia, por parte de esta última, de productos destinados al aislamiento térmico. En estos contratos se incluyó una cláusula arbitral (bajo las reglas de la CCI) y se estipuló que cualquier subsidiaria de Dow Chemical Company podía realizar las entregas necesarias, según lo requerido contractualmente, aunque en la práctica fueran efectuadas por Dow Chemical (sociedad en Francia) ${ }^{62}$.

Con motivo de diversas controversias originadas durante la ejecución del contrato, Isover Saint Gobain demandó ante los tribunales franceses a varias de las subsidiarias de Dow Chemical Company. En respuesta a lo anterior, tres filiales del grupo Dow Chemical y la matriz, radicada en Estados Unidos, iniciaron un procedimiento arbitral según estaba estipulado en el contrato. Ante esto, Isover Saint Gobain alegó la inexistencia de una cláusula arbitral que lo vinculara con la filial francesa y con la matriz norteamericana (Dow Chemical Company) y solicitó que fueran excluidas del arbitraje, ya que ninguna de ellas había sido signataria de la cláusula.

Sin embargo, en resumen de Caviano, en este caso "el tribunal arbitral [...] aceptó la legitimación para participar en el juicio arbitral (como demandantes) de dos sociedades del Grupo Dow no signatarias del acuerdo arbitral, bajo el argumento de que «la cláusula arbitral expresamente aceptada por determinadas sociedades del grupo económico debe obligar a las otras que, en virtud del rol que les cupo en la celebración, ejecución o rescisión de los contratos que contienen la cláusula arbitral y de acuerdo con la común intención de todas las partes del juicio arbitral, parecen haber sido verdaderas partes en los contratos o estuvieron ampliamente comprometidas en ellos y en los conflictos que de ellos surgieron»" 63 .

Como venimos explicando, no basta con que la sociedad no signataria pertenezca al grupo de empresas para entender que es parte en el contrato que otra sociedad del mismo haya pactado. Es decir, la extensión de los efectos de la cláusula compromisoria contenida en dicho contrato

\footnotetext{
62 SuÁrez (2005) 61.

63 Caviano (2006) 125. En este sentido, SuÁrez hace notar que "de la lectura de la decisión se desprende que la razón central estaba relacionada con la existencia de un consentimiento implícito" entre las sociedades que eran parte del contrato. SuÁrez (2005) 62. Llama la atención en este caso, el hecho de que no se hayan extendido los efectos del convenio para atraer a un tercero para ser demandado en sede arbitral, sino para permitir la legitimación activa de quien aparece como un tercero ante la relación jurídica.
} 
no puede llevarse a cabo de manera automática por ese solo hecho, ya que implicaría desconocer arbitrariamente la pluralidad e independencia jurídica que existe entre los componentes del grupo, y generaría un nivel de incerteza jurídica preocupante. Más bien, lo que se busca, tomando como presupuesto la unidad económica en el grupo, es el consentimiento implícito de ser parte de la relación contractual. Así, como explican BLACKABy y PARTAsides, cuando un tribunal debe determinar si un tercero no signatario debe ser vinculado por un acuerdo arbitral, se centrará en la intención común de las partes, pudiendo considerar una serie de factores, tales como si el tercero participó activamente en el contrato que contiene la cláusula arbitral ${ }^{64}$; si tiene un claro interés en el resultado del juicio originado por dicha cláusula; o si el tercero es parte de un contrato que se encuentra íntimamente entrelazado con aquel a partir del cual ha surgido una disputa ${ }^{65}$.

En términos prácticos, VÁsQUEZ señala que la extensión de los efectos de la cláusula arbitral a empresas que no comparecieron formalmente el convenio "se convierte en una cuestión de prueba fáctica que tendrá que ser valorada por los árbitros a la hora de aceptar o denegar su propia competencia para incluir a unas u otras sociedades en la relación jurídico arbitral. En tal sentido, los efectos del convenio arbitral no pueden ser extendidos a las sociedades no firmantes que tengan personalidad jurídica distinta, excepto si han sido representadas efectiva o implícitamente o si han desempeñado un papel activo en las negociaciones objeto de la controversia (participación efectiva)"66. Así, tal como lo hizo la corte en el

64 Aguilar cuestiona si acaso extender los efectos de la cláusula en atención al consentimiento implícito de formar parte de la relación sustancial no vulneraría el principio de la autonomía de la cláusula arbitral. En otras palabras, si más bien no debiera buscarse una voluntad implícita en relación directa con la cláusula compromisoria más que con el resto del contrato. Sin embargo, luego de hacer un análisis de dicho principio, concluye que este tiene otros objetivos tales como la posibilidad de discutir acerca de la validez del contrato que contiene la cláusula en sede arbitral o evitar obstaculizar el arbitraje con cada discusión sobre dicha validez. Pero que "lo que el principio de autonomía de la cláusula compromisoria no puede exigir es que el consentimiento de la cláusula arbitral se manifieste de forma autónoma y distinta al del contrato principal, ya que la existencia de dos actos jurídicos autónomos no es compatible con la existencia de un solo intercambio de consentimientos". AguiLar (2001) 226. De modo que la manifestación de voluntad de participar del contrato necesariamente lleva aparejada la de acceder a método de solución de conflictos establecido en el mismo. Aguilar (2001) 220-227.

65 Blackaby/Partasides (2015) 87.

66 VÁsQuez (2009) 409. En este sentido, como se verá más adelante, para poder hacer efectiva la extensión de los efectos de la cláusula arbitral al no signatario, será necesario el reconocimiento del principio Kompetenz-Kompetenz en la ley que regule el arbitraje. En virtud de dicho principio, será el mismo árbitro quien decidirá sobre su propia competencia, ya que es él quien debe resolver todos los conflictos derivados del convenio. Una explicación de dicho instituto, así como su acogida jurisprudencial en VÁsQuez (2009) 211-219. Nos referiremos a este tema más adelante, en el punto 5.1. 
caso explicado anteriormente, se trata de hacer primar la realidad económica a partir de los hechos para descubrir el consentimiento implícito en el componente del grupo.

\section{(4.3.) PRESCINDENCIA DE LA PERSONALIDAD JURÍdiCA}

Como bien señala Orrego, la regla general en los arbitrajes en que intervienen personas jurídicas "ha sido y continúa siendo que los jueces y árbitros deben respetar las personalidades jurídicas diferentes y, por consiguiente, que la cláusula de arbitraje solo tendrá efectos respecto de las partes en el contrato. Sin embargo, no es menos cierto que las realidades contemporáneas de los negocios han llevado al reconocimiento de muchas excepciones a esa regla" 67 . A diferencia de lo que ocurría en las teorías del grupo anterior, aquí no se busca extraer un consentimiento implícito del no signatario a partir de sus conductas o de su participación en el grupo de sociedades. De lo que se trata es de ignorar o pasar por alto la personalidad jurídica de una entidad cuya independencia de aquella que es parte en el contrato, es ficticia o aparente.

En un sentido similar, PARK señala que, "en contraste con el consentimiento implícito, la prescindencia de la personalidad jurídica se construye en base a factores tales como el fraude o la subcapitalización. A pesar de la intención de las partes, la entidad jurídica que firmó la cláusula de arbitraje desaparece, y un accionista responde por sus obligaciones corporativas. Al acabar su existencia legal independiente (para efectos del

67 Orrego Vicuña, Francisco (2011). "La extensión de la cláusula de arbitraje a terceros: Realidades económicas y ficciones jurídicas” en Soto Coaguila, Carlos Alberto (Dir.), Tratado de Derecho Arbitral. El Convenio Arbitral, Bogotá: Grupo Editorial Ibańez, T. I, pp. 363383, p. 365. Si bien pareciera existir una gran similitud entre el fundamento aquí señalado y el correspondiente a la teoría del grupo de sociedades, el autor hace una distinción que resulta particularmente ilustrativa al señalar que "Algunas de esas excepciones se refieren a casos en que una personalidad jurídica separada es creada con la intención de quebrantar la ley, el orden público o la buena fe, o para frustrar los derechos de terceros. [...] Otras excepciones, sin embargo, han sido aceptadas en decisiones de las cortes de justicia y de los tribunales de arbitraje sin que haya relación con algún propósito avieso. En muchos casos se requiere de la existencia de una intención, aun cuando implícita, de que todas las partes, inclusive las que no han firmado el contrato, desean que se les aplique tanto ese contrato como la cláusula de arbitraje. El papel que hayan tenido esos no signatarios en la conclusión y ejecución del contrato será determinante de la existencia de esa intención”. Orrego (2011) 365-366. En este sentido, la teoría del grupo de sociedades se enmarcaría con mayor facilidad en el segundo supuesto. Sin embargo, consideramos que lo fundamental ahí, más que la prescindencia de la personalidad jurídica, es la intención implícita de participar en el arbitraje a la que alude el autor. 
arbitraje), la sociedad signataria le deja a su propietaria o afiliada los derechos y obligaciones emanados del arbitraje" 68 .

De este modo, "cuando la ficción jurídica se utiliza para violar la ley o el orden público o para perjudicar los intereses y derechos de los terceros, el derecho debe intervenir porque se está en presencia de abusos de la personalidad jurídica" ${ }^{69}$. En estos casos, es necesario desconocer la personalidad jurídica. Para estos efectos, a doctrina ha elaborado una serie de teorías del abuso de la personalidad jurídica, tales como la simulación, la representación o agencia, el levantamiento del velo corporativo y el alter ego entre otros ${ }^{70}$.

\section{(4.3.1.) El levantamiento del velo corporativo}

El levantamiento del velo corporativo, reconocido prácticamente en todos los ordenamientos jurídicos ${ }^{71}$, consiste en hacer caso omiso de la personalidad jurídica de una entidad cuya individualidad e independencia legal son tan solo ficciones elaboradas con fines generalmente fraudulentos. En explicación de Blackaby y Partasides, "Una corte o tribunal podría concluir que un tercero se encuentra obligado por un acuerdo de arbitraje cuando hay evidencia de que la entidad que es parte en el acuerdo está siendo usada como un 'instrumento o fachada' con el fin de evitar u ocultar la responsabilidad del primero" 72 .

En cuanto a su origen, se ha dicho que los "países bajo el sistema del common law, precisamente por la flexibilidad del mismo, son los primeros en desarrollar una teoría para poner remedio a los abusos que se cometían bajo el amparo de la personalidad jurídica. Se inicia de esta manera con la doctrina conocida como Disregard of legal entity (desentenderse de la

68 PARK (2009) 4. La traducción es nuestra, el texto original señala: In contrast to implied consent, disregard of corporate personality builds on factors such as fraud or undercapitalization. Regardless of the parties' intent, the legal entity that signed the arbitration clause disappears, and a shareholder answers for its corporate obligations. In ceasing its separate legal existence (for purposes of the arbitration), the signatory company leaves its owner or affiliate to inherit arbitration rights and duties.

69 García-Bolívar, Omar (2007). "El desconocimiento de la personalidad jurídica en el arbitraje internacional de inversiones" en Revista Internacional de Arbitraje, enero-junio, pp. 113-145, p. 121.

70 García-Bolívar (2007) 121-123.

71 Aguilar (2001) 321-322. Así, en los países de tradición anglosajona se le conoce como Lifting o Piercing the corporate veil; mientras que en el derecho francés se habla de un abus de droit y en el alemán de Durchgriff, que se relaciona con el aprovechamiento de la personalidad jurídica. PARK (2009) 16-17.

72 Blackaby/Partasides (2015) 88. La traducción es nuestra, el texto original señala: “ $A$ court or tribunal may conclude that a third party is bound by an arbitration agreement where there is evidence that the party to the agreement is being used as 'a device or façade' in order to avoid or conceal liability". 
entidad legal) o Lifting of [sic. or] piercing the corporate veil (levantar o correr el velo corporativo), en épocas de la gran guerra para determinar la nacionalidad de las sociedades"73. En efecto, "se planteó el problema de si a una sociedad nacional cuyo capital mayoritario se encontraba en manos de extranjeros pertenecientes a una nación enemiga, podía esta ser considerada como sociedad enemiga, a efectos de la aplicación de determinadas normas imperantes en aquel momento de contienda"74. Más allá del uso que se haya dado a esta teoría en un principio, lo cierto es que con el paso de los años, los distintos ordenamientos fueron aplicando el mismo criterio para desestimar la personalidad jurídica ante los abusos de la misma que pudieran realizar los distintos agentes del comercio, con el fin de evitar la aplicación del derecho. Así, la doctrina del levantamiento del velo societario también ha tenido aplicación en materia tributaria, de quiebras, libre competencia, etc.

Respecto de los requisitos identificados por la doctrina para la aplicación de esta teoría, por un lado, los pronunciamientos doctrinarios han sido múltiples. Juppet señala que, al menos según los estándares de la Corte Suprema de Estados Unidos, se requiere, en primer lugar, "la unidad de intereses con los dueños de la organización, lo que puede ser probado por la falta de cumplimiento de las formalidades corporativas, como reuniones de directorio o contabilidad separada. Y, en segundo lugar, que las consecuencias de los actos realizados por la compañía impliquen un resultado injusto o inequitativo" 75 . En sentido similar, Aguilar seńala tres requisitos. En primer lugar, que respecto de la transacción respectiva, la sociedad controladora tenga un completo dominio en términos financieros y de dirección sobre la controlada, de modo que esta última no haya

73 Arrubla Paucar, Jaime Alberto (2010). "El levantamiento del velo corporativo en Colombia” en León RobaYo, Edgar Iván; Rincón CÁrdenas, Erick y López Castro, Yira (editores): Levantamiento del velo corporativo. Panorama y perspectivas. El caso colombiano, Bogotá: Editorial Universidad del Rosario, pp. 59-78, p. 60. La flexibilidad aludida por el autor está dada principalmente por la aplicación del principio de equidad (equity), propio de los países de raigambre anglosajona. En este sentido, afirma Arrubla más adelante, "el criterio de equidad se presta perfectamente como principio que sustenta la teoría. Esto no sería lo mismo para el sistema jurídico continental, en el que aparecería el criterio de equidad como gaseoso y demasiado vago para soportar la aplicación del abuso de la personalidad jurídica”. Arrubla (2010) 64-65. Sin perjuicio de lo anterior, el criterio de la equidad ha encontrado cabida en nuestro medio, mediante un reconocimiento tanto legal como jurisprudencial, y principalmente en la práctica arbitral interna. Una explicación del origen y contenido de la equidad, así como sus proyecciones en el derecho chileno y en la jurisprudencia arbitral en Romero/Díaz (2016) 79-101.

74 Seijas Rengifo, Teresa de Jesús (2007). "The Disregard of the legal entity" en Revista de Derecho y Ciencia Politica, UNMSM, Vol. 64 (No 1 - No 2), pp. 397-426, p. 399.

75 Juppet Ewing, María Fernanda (2011). "Algunas consideraciones acerca de la responsabilidad de las personas jurídicas y de los agentes que las dirigen” en Revista Actualidad Jurídica, No 24, Año XII, pp. 209-226, p. 215. 
tenido una voluntad propia en el negocio. En segundo lugar, que exista una conducta fraudulenta o injusta. Y finalmente, se requiere un nexo causal entre el excesivo control y el daño que se ha causado mediante la conducta fraudulenta ${ }^{76}$.

Asimismo se ha pronunciado HuI, que junto con repetir varios de los criterios anteriormente expuestos para determinar la procedencia del levantamiento del velo corporativo ${ }^{77}$, hace énfasis en la aplicación restrictiva de esta teoría. En efecto, señala que "las Cortes solo van a perforar el velo corporativo en circunstancias graves. Para levantar el velo y llegar a la sociedad matriz, el control de esta sobre la subsidiaria debe ser tan completo que ambas sean virtualmente una misma- la subsidiaria es la mera instrumentalidad de la sociedad matriz"78

Ahora bien, con el fin de atenuar la posible inseguridad jurídica que podría surgir de la desestimación de la individualidad de la persona jurídica, la doctrina alemana ha distinguido entre diversos grupos de casos dentro de la misma. Así, algunos casos responden a la infracapitalización (Unterkapitalisierung), al control o dirección de una sociedad sobre otra (Fremdbeherrschung ${ }^{79}$ oder Fremdsteuerung), a la confusión de patrimonios (Vermögens- oder Sphärenvermischung) o al abuso de la persona jurídica en fraude a la ley o en incumplimiento de obligaciones (Institutsmissbrauchs ${ }^{80}$. En este sentido, podemos apreciar como muchas

Aguilar (2001) 333-334.

Hui, Alexandra Anne (2007). "Equitable Estoppel and the Compulsion of Arbitration" en Vanderbilt Law Review, Vol. 60, No 2, pp. 711-744, p. 724. La autora señala como criterios usados por las cortes para determinar el levantamiento del velo corporativo los siguientes: "(1) the absence of the formalities and paraphernalia that are part and parcel of the corporate existence, i.e. issuance of stock, election of directors, keeping of corporate records and the like, (2) inadequate capitalization, (3) whether funds are put in and taken out of the corporation for personal rather than corporate purposes, (4) overlap in ownership, officers, directors, and personnel, (5) common office space, address and telephone numbers of corporate entities, (6) the amount of business discretion displayed by the allegedly dominated corporation, (7) whether the related corporations deal with the dominated corporation at arm's length, (8) whether the corporations are treated as independent profit centers, (9) the payment or guarantee of debts of the dominated corporation by other corporations in the group, and (10) whether the corporation in question had property that was used by other of the corporations as if it were its own."

Hui (2007) 724. La traducción es nuestra, el texto original expresa: "Courts will only pierce the corporate veil in egregious circumstances. To pierce the veil to reach the parent company, the parent's domination and control of the subsidiary must be so complete that the two are virtually one and the same-the subsidiary is the mere instrumentality of the parent corporation".

La traducción literal de este término se refiere más bien a la situación de dominio -o dominación- de una empresa sobre otra; mientras que el Fremdsteuerung se refiere más al control ejercido por una entidad extraña. Sin perjuicio de dicha distinción, por regla general, cuando se da una situación de dominio de una empresa por otra, producto de la tenencia de la totalidad o la mayoría de las acciones de la primera, lo normal es que vaya aparejado el control por parte de la "empresa dominante" sobre la "dominada", lo cual podría variar según la estructura societaria.

Aguilar (2001) 322. Nota al pie 216. 
de estas situaciones pueden justificar la aplicación de esta teoría para extender los efectos del acuerdo arbitral a un tercero aparente. Lo anterior se verifica de modo particular respecto de la Institutsmissbrauchs, toda vez que ese abuso o incumplimiento de las obligaciones se vuelve patente cuando una sociedad ficticia es utilizada como pantalla para pactar un contrato cuyas obligaciones o cláusulas serán desconocidas con posterioridad por la matriz, invocando la independencia legal de la empresa. En este sentido, la doctrina ha reconocido como uno de los efectos propios de la aplicación de la doctrina del levantamiento del velo corporativo la "imputación de ciertos actos no realizados directamente" 81 .

Aquí ya nos enmarcamos en la utilización de la doctrina del levantamiento del velo corporativo para hacer extensivos los efectos de la cláusula arbitral a la entidad o a los socios que están detrás de la compañía que, usada como pantalla ${ }^{82}$, pactó el contrato que contiene dicha cláusula. En definitiva, será necesario levantar el velo corporativo cuando la sociedad que comparece al acuerdo no es más que una compañía de papel, y entender como parte en el arbitraje a los socios de la misma o a la entidad que la controla, a pesar de no haber firmado el contrato o la cláusula. En este sentido, la doctrina comparada ha reconocido que "en el contexto del arbitraje internacional, el levantamiento del velo corporativo conlleva traer a las partes que no han firmado el acuerdo de arbitraje" 83 . De lo que se trata aquí, no es de descubrir un consentimiento implícito en la sociedad que es traída al arbitraje, sino de responder a la conducta fraudulenta del agente de comercio que abusa de su personalidad jurídica, mediante la desestimación de la misma; y junto con ello, velar por la eficacia y correcta substanciación del arbitraje. Es más, en este caso la voluntad del tercero no signatario es precisamente la contraria a ser alcanzado por los efectos del acuerdo arbitral. Junto con lo anterior se busca proteger a los cocontratantes de la empresa cuya personalidad jurídica se desestima,

81 Seijas (2007) 401

82 Constituye un presupuesto básico de esta doctrina el hecho de que la empresa cuya personalidad jurídica se desestima no sea más que una fachada utilizada por los accionistas o un alter ego de la sociedad controladora. Así, se han seńalado una serie de factores a los cuales se pueden recurrir para identificar una sociedad de este tipo, tales como el "incumplimiento de formalidades societarias; inadecuada capitalización; confusión de patrimonios; superposición de dueños, directores y personal; oficinas y números de teléfono comunes; el grado de discrecionalidad que muestra la sociedad controlante; el funcionamiento como unidades de negocio o de ganancias conjuntas; la asunción de deudas o el establecimiento de garantías, por parte de la controlante, respecto de deudas de la subsidiaria" etc. Caviano (2006) 134.

83 Kryvor, Yaraslau (2011). "Piercing the corporate veil in international arbitration" en Global Business Law Review, Vol. 1, pp. 169-186, p. 173. La traducción es nuestra, el texto original expresa "In the context of international arbitration, piercing the corporate veil involves bringing in the parties that have not signed an arbitration agreement". 
toda vez que - de un modo similar a lo que ocurre en la doctrina de los actos propios- ha creado una apariencia de unidad.

Sin embargo, cabe señalar que la doctrina ha hecho una distinción entre la utilización de la teoría en estudio para hacer efectiva la responsabilidad de la sociedad matriz por las actuaciones de su filial (que en realidad sería un alter ego de la primera); y, por otro lado, para extender el ámbito de aplicación subjetivo de la cláusula de arbitraje, sometiendo a la matriz a una jurisdicción que en principio no le correspondería. En efecto, solo para el primer caso se requeriría el elemento de fraude, mientras que para el segundo solo se exigiría "un alto grado de control o, incluso, el de la suficiente 'integración económica" ${ }^{44}$. Sin embargo, no hay que olvidar que "la utilización de esta doctrina, en tanto implica aniquilar el principio de la personalidad jurídica de las sociedades, ha sido conceptuado como un remedio de excepción, cuyo objetivo es evitar la consumación de un fraude a terceros" 85 , y en este sentido consideramos que deben existir razones proporcionadas para hacer comparecer en un arbitraje a una entidad que no lo ha suscrito, como lo es el elemento fraudulento en el abuso de la personalidad jurídica, manifestado en hechos $\operatorname{concretos}^{86}$.

No nos parece suficiente motivo para efectuar dicha ampliación subjetiva, la mera existencia del referido grado de control o "integración económica”, ya que implica olvidar el carácter de excepcionalidad de todos los supuestos que venimos estudiando, más allá de que no se busque, en el caso concreto, hacer efectiva la responsabilidad de una sociedad por los actos de la otra.

84 Aguilar (2001) 335. La autora sostiene que "también ha de ser posible levantar el velo social, a efectos de atribuir la competencia a los árbitros, sin que ello signifique hacer a la matriz responsable por los actos de su filial [...], la prueba de que una sociedad domina la política, las finanzas así como la práctica comercial de otra, de tal modo que pueda considerarse que esta última sociedad carece da una voluntad y de una existencia independiente, debe estimarse como suficiente para proceder a un juicio único, eso es, para someter a la primera sociedad a la vía arbitral que la segunda ha pactado”. Aguilar (2001) 335.

85 Roque (2006) 133.

86 En ese sentido, TANG da cuenta de este requisito al señalar: "according to the alter ego doctrine, a corporation may be bound by an agreement entered into by its shareholders regardless of the agreement's structure or the shareholders' attempts to bind itself alone to its terms, where their conduct demonstrates a virtual abandonment of separatenes". TANG (2009) 24. En este sentido, sin dicha conducta que demuestra un abandono virtual de la independencia jurídica de las compañias (como podría serlo tanto la conducta fraudulenta como el consentimiento implícito mediante la participación en el contrato), no sería posible desestimar la personalidad jurídica en aplicación de esta teoría. 


\section{5) APLICACIÓN DE LAS HIPÓTESIS DE EXTENSIÓN EN LA LACI}

Habiendo revisado brevemente algunos de los supuestos en que la doctrina nacional y comparada ha encontrado justificación para la extensión de los efectos de la cláusula arbitral a los no signatarios, corresponde ahora analizar la procedencia que podría encontrar esta técnica en el marco de la LACI.

En este sentido, Romero ha señalado que "la regulación legal del arbitraje comercial internacional contiene varios elementos que podrían facilitar la extensión del convenio arbitral a terceros no signatarios, naturalmente, si se cumplen los supuestos teóricos y fácticos para hacer esta excepción" 87 . De hecho, por sentencia de 30 de diciembre de 2011, el Presidente de la Ilustrísima Corte de Apelaciones de Santiago validó la extensión de los efectos del acuerdo arbitral a un tercero no firmante por aplicación de la figura de la estipulación en favor de un tercero precisamente conociendo del recurso especial contemplado en el artículo $16 \mathrm{~N}^{\circ}$ 3 de la $\mathrm{LACI}^{88}$.

En este sentido, vamos a revisar si en nuestra legislación se dan aquellas condiciones necesarias para que el árbitro pueda hacer efectiva dicha extensión. Entre otras, deben darse las siguientes situaciones:

\section{(5.1) CONSAGRACIÓN DEL PRINCIPIO KOMPETENZ-KOMPETENZ}

Como cuestión procesal previa, es necesario que el árbitro esté facultado para decidir acerca de su propia competencia para poder hacer efectiva la extensión del acuerdo a la parte no signataria. Como ya se dijo al principio, la competencia del árbitro está dada de un modo excepcional a partir del consentimiento de las partes de someter una determinada controversia al conocimiento del árbitro, y en ese sentido, se limitada a las personas que han manifestado tal consentimiento, por tanto, la extensión subjetiva del arbitraje corresponde a una cuestión acerca de la competencia del árbitro. Así, para hacer comparecer al arbitraje a un tercero aparente, sin tener que resolver ante los jueces ordinarios de manera previa la efectividad de algún supuesto que justifique considerarlo como parte, es necesario que dicha cuestión acerca del alcance subjetivo de la competencia del árbitro sea resuelta por él mismo.

\footnotetext{
$87 \quad$ Romero (2012) 6.

88 Una exposición del caso en VÁsquez Palma, María Fernanda (2015). "Ley chilena de arbitraje comercial internacional: Análisis de las doctrinas jurisprudenciales, a diez años de su vigencia” en Revista Ius et Praxis, Ańo 21, N², pp. 523-552, p. 526.
} 
La facultad del árbitro para decidir acerca de su propia competencia, es lo que la doctrina ha llamado el principio "kompetenz-kompetenz". De origen alemán ${ }^{89}$, este principio cuenta con un amplio reconocimiento en el derecho comparado y consiste en que "debe ser el propio árbitro quien debe resolver todos los conflictos derivados del convenio arbitral, incluida la posible alegación de nulidad del contrato del cual puede formar parte el pacto arbitral y aún de este último, lo que se resume en la idea que el árbitro tiene competencia para revisar su propia competencia" 90 .

Como puede apreciarse, la consagración de este principio permite que se demande en sede arbitral de manera directa a las personas o entidades que son terceros aparentes; de modo que, ante la eventual alegación

89 En efecto, se ha señalado que este principio habría tenido su origen "en un fallo emitido por un tribunal Superior en la República Federal de Alemania en el año 1955. En el mismo se determinó que debía atribuírseles a los árbitros la facultad de tanto de determinar el alcance del acuerdo arbitral como de su competencia y autoridad hacia el mismo". V́́sQuez Palma, María Fernanda (2011). "Recepción del Arbitraje Comercial Internacional en Chile desde una óptica jurisprudencial. Una revisión ineludible" en Revista Chilena de Derecho, Vol. 38, $n^{\circ} 2$, pp. 349-370, p. 357, nota al pie no 17.

90 VÁsQuEZ (2009) 211. De la formulación transcrita se desprende la estrecha relación entre este principio y el de la autonomía del convenio arbitral. En efecto, el principio de autonomía del acuerdo arbitral implica, básicamente, que la nulidad o invalidez del contrato en que se enmarca el acuerdo arbitral no implica necesariamente la de la cláusula compromisoria; de modo que si en un arbitraje se alega la nulidad de dicho contrato, no por ese hecho deberá el árbitro abstenerse de pronunciarse sobre tal asunto. En este sentido, la autonomía del acuerdo arbitral, "para un sector de la doctrina, constituye un pilar sobre el que se funda el principio kompetenz-kompetenz." Minorini Lima, Ignacio J. (2011). "La autonomía del acuerdo de arbitraje en el derecho argentino" en Sото Coaguila, Carlos Alberto (Dir.), Tratado de Derecho Arbitral. El Convenio Arbitral, Bogotá: Grupo Editorial Ibañez, T. I, pp. 189-198, pp. 191-192. Sin embargo, como señala Hernández, "los principios de autonomía de la cláusula arbitral y el de kompetenz-kompetenz, operan conjuntamente para asegurar la efectividad del procedimiento arbitral, y aunque se sobreponen y mantienen similitudes, es importante distinguirlos para establecer la importancia de cada uno". Hernández BoteRO, Héctor (2011). "La autonomía de la cláusula arbitral en el arbitraje comercial internacional: reflexiones y problemáticas de la experiencia colombiana" en Soto CoAguila, Carlos Alberto (Dir.), Tratado de Derecho Arbitral. El Convenio Arbitral, Bogotá: Grupo Editorial Ibánez, T. I, pp. 401-415, p. 413. En cuanto a la relación entre uno y otro principio, nos parece pertinente transcribir la explicación de Gaillard y Savage que cita el mismo autor: "los dos principios funcionan en dos etapas en las cuales sutilmente se superponen y complementan mutuamente. Así, el principio de la autonomía de la de la cláusula arbitral es la primera etapa de la determinación de su competencia para conocer el asunto. Este les permite a los árbitros examinar su propia competencia a la luz de la validez y existencia del contrato principal. En una segunda instancia, el principio de kompetenz-kompetenz va más allá, pues permite resolver su competencia a la luz de las controversias dirigidas directamente contra el pacto arbitral. [...] así, el principio de la autonomía de la cláusula arbitral protege la cláusula frente a controversias relacionadas con la existencia y validez del contrato principal, pero no habilita a los árbitros para proceder con el arbitraje en el caso en que la supuesta invalidez afecte directamente el acuerdo arbitral. Esta es una consecuencia únicamente del principio kompetenz-kompetenz." Hernández (2011) 413-414. Sin embargo, en este caso no se trata de resolver sobre la validez o nulidad del convenio arbitral ni del contrato donde se enmarca la cláusula compromisoria, sino de determinar el alcance subjetivo de las mismas, lo cual, como dijimos, forma parte de la competencia del árbitro. 
de incompetencia del árbitro por no estar ellos comprendidos dentro del ámbito subjetivo sobre el cual el compromisario ejerce su jurisdicción, se producirá un incidente que tendrá que resolverse en el mismo arbitraje, sin que este deba detenerse, o incluso ser resuelto en la sentencia definitiva. Lo mismo ocurrirá cuando una parte que no ha comparecido formalmente al acuerdo arbitral, pero que debe ser considerada como parte del mismo en virtud de alguno de los supuestos aquí mencionados, desea hacer valer sus pretensiones ante el árbitro. De este modo, como ya mencionamos anteriormente, la verificación de los supuestos fácticos que hacen posible la consideración de dicho tercero aparente como parte en el arbitraje, será una cuestión probatoria que deberá resolver el propio árbitro a la hora de pronunciarse sobre su propia competencia. Serán las propias partes quienes busquen demostrar la existencia o inexistencia de algunas de las figuras que venimos estudiando.

En Chile, nuestra legislación en materia de arbitraje comercial internacional, la Ley No 19.971, recoge este principio en su artículo 16 no 1 , que señala:

Artículo 16. - Facultad del tribunal arbitral para decidir acerca de su competencia.

1) El tribunal arbitral estará facultado para decidir acerca de su propia competencia, incluso sobre las excepciones relativas a la existencia o a la validez del acuerdo de arbitraje. A ese efecto, una cláusula compromisoria que forme parte de un contrato se considerará como un acuerdo independiente de las demás estipulaciones del contrato. La decisión del tribunal arbitral de que el contrato es nulo no entrañará ipso jure la nulidad de la cláusula compromisoria.

2) La excepción de incompetencia del tribunal arbitral deberá oponerse a más tardar en el momento de presentar la contestación. Las partes no se verán impedidas de oponer la excepción por el hecho de que hayan designado a un árbitro o participado en su designación. La excepción basada en que el tribunal arbitral ha excedido su mandato deberá oponerse tan pronto como se plantee durante las actuaciones arbitrales la materia que supuestamente exceda su mandato. El tribunal arbitral podrá, en cualquiera de los casos, estimar una excepción presentada más tarde si considera justificada la demora.

3) El tribunal arbitral podrá decidir las excepciones a que se hace referencia en el numeral 2) de este artículo como cuestión previa o en un laudo sobre el fondo. Si, como cuestión previa, el tribunal arbitral se declara competente, cualquiera de las partes, dentro de los treinta dias siguientes al recibo de la notificación de esa decisión, podrá solicitar del Presidente de la respectiva Corte de Apelaciones que resuelva la cuestión, y la re- 
solución de este tribunal será inapelable; mientras esté pendiente dicha solicitud, el tribunal arbitral podrá proseguir sus actuaciones y dictar un laudo.

De la lectura de esta norma, podemos establecer que al amparo de la LACI, al menos en términos procesales, la consagración del principio kompetenz-kompetenz permite que se materialice ante el árbitro la extensión de los efectos del convenio arbitral a los terceros aparentes.

\section{(5.2) UN ESCASO FORMALISMO EN EL ACUERDO ARBITRAL}

Un segundo tema que debe ser tenido en cuenta a la hora de analizar la factibilidad de la extensión de los efectos del arbitraje, tiene que ver con las exigencias formales del acuerdo arbitral ${ }^{91}$. En este sentido, la LACI permite una mayor flexibilidad para la aplicación de eta técnica, atendido que solo exige que el acuerdo arbitral conste por escrito para tener validez formal. En efecto, los requisitos formales establecidos en la LACI para el convenio de arbitraje están señalados en su artículo 7o:

Articulo $7^{\circ}$ - Definición y forma del acuerdo de arbitraje.

1) El "acuerdo de arbitraje" es un acuerdo por el que las partes deciden someter a arbitraje todas las controversias o ciertas controversias que hayan surgido o puedan surgir entre ellas respecto de una determinada relación juridica, contractual o no contractual. El acuerdo de arbitraje podrá adoptar la forma de una cláusula compromisoria incluida en un contrato o la forma de un acuerdo independiente.

2) El acuerdo de arbitraje deberá constar por escrito. Se entenderá que el acuerdo es escrito cuando esté consignado en un documento firmado por las partes o en un intercambio de cartas, télex, telegramas u otros medios de telecomunicación que dejen constancia del acuerdo, o en un intercambio de escritos de demanda y contestación en los que la existencia de un acuerdo sea afirmada por una parte sin ser negada por la otra. La refe-

91 Es necesario señalar que este aspecto solo cobra relevancia cuando se trata de hacer efectiva la extensión en virtud de alguno de los supuestos teóricos que basados en el consentimiento implícito del tercero. Esto, porque lo que se analiza al tener en cuenta los requisitos formales del acuerdo arbitral, es si el consentimiento expresado por una parte mediante actos distintos al de comparecer formalmente al convenio arbitral, es suficiente para que pueda ser considerado como parte en el arbitraje. Lo anterior no se da en aquellas situaciones donde lo que se hace es desestimar la personalidad jurídica, ya que en ese caso no se centra la mirada en el consentimiento dado por el tercero, sino en su posible identificación con la persona o entidad que sí compareció formalmente a la constitución del arbitraje, de modo que no hay dudas acerca de la validez de dicha manifestación de voluntad: lo que se hará será considerar que en ese consentimiento estaba realmente incluido el tercero aparente. 
rencia hecha en un contrato a un documento que contiene una cláusula compromisoria constituye acuerdo de arbitraje siempre que el contrato conste por escrito y la referencia implique que esa cláusula forma parte del contrato.

La primera conclusión a la que se arriba de la lectura de este artículo, es que la firma del acuerdo no constituye un requisito para la validez del convenio, sino que solo podría constituir un elemento probatorio. En este sentido, como señala Graham, "en ausencia de una firma, la existencia de la cláusula compromisoria puede ser comprobada por cualquier otro medio, como testimonios por ejemplo" 92 . De modo que, al menos en cuanto a la firma, queda claro que rige la desformalización.

Ahora bien, el requisito de la escrituración del acuerdo podría significar un impedimento para la extensión de los efectos del mismo a quienes no han comparecido formalmente. En efecto, la LACI establece un mínimo de formalidad -que el acuerdo esté por escrito- que en algunas ocasiones ha significado precisamente rechazar la inclusión de terceros en países que consagran el mismo requisito ${ }^{93}$. Así, en ausencia de una declaración escrita, no podrá extenderse a un tercero aparente los efectos de un

92 Graham (2008) 176.

93 Comenta Orrego un caso en que se debatía la inclusión en el arbitraje de una filial de la demandada que no había firmado el contrato pertinente, pero que había participado en la ejecución del mismo. El tribunal decidió que el acuerdo arbitral debía regirse por la Ley federal suiza de Derecho Internacional Privado de 1987, cuyo artículo $178^{\circ}$ (1) dispone: Quant à la forme, la convention d'arbitrage est valable si elle est passée par écrit, télégramme, télex, télécopieur ou tout autre moyen de communication qui permet d'en établir la preuve par un texte. De modo que el requisito de validez era el mismo que el establecido por la LACI: constar por escrito. Y concluyó que no era procedente la extensión de la cláusula arbitral a la filial por no haberse probado por escrito el acuerdo, no obstante su participación en la relación contractual. Cabe mencionar que, como reconoce el autor, los tribunales suizos "han sido tradicionalmente más exigentes respecto del cumplimiento de la condición de validez formal indicada”. Orrego (2011) 373. Sin embargo, en el derecho Suizo el tema tampoco está zanjado. En efecto, como señala MülLER, "There has been, and still is, much debate in Switzerland whether the form requirement only applies to the arbitration agreement between the original parties, or whether it also applies to the third party" y más adelante se refiere a una postura doctrinal que entiende que los requisites establecidos en el artículo $178^{\circ}$ (1) de la Federal Private International Law Act (PILA) solo servirían para constatar la existencia del acuerdo arbitral, mientras que para la extensión de los efectos del mismo a terceros debía probarse que el acuerdo se ha ejecutado entre las partes: According to another and more liberal view, held primarily by Blessing, the form requirement set out in Article 178(1) of the PILA only refers to the mere existence of a validly signed arbitration agreement (Blessing, Introduction to Arbitration - Swiss and International Perspectives, Basel 1999, N 504). Blessing holds that the extension of an arbitration agreement to a third party is in fact not a form issue of Article 178(1) of the PILA, but rather of Article 178(2) of the PILA, in relation to the scope of an existing and validly executed arbitration agreement. Therefore, according to Blessing, once an arbitration clause exists, its scope and reach have to be determined according to Article 178(2) of the PILA, as a matter of proper contract construction and interpretation, in order to find out if the arbitration agreement was meant to also include a non-signatory third party. MüLLER (2009) 10. 
acuerdo arbitral a pesar de haber actuado de modo tal que deba entenderse incluido en el arbitraje.

Por otra parte, si hacemos una interpretación más flexible del artículo $7^{\circ}$ de la LACI podemos entender que el requisito formal de constar por escrito se refiere solo a la existencia misma del acuerdo arbitral, y no a la manera en que debe concurrir específicamente el consentimiento de todas las partes, de modo que "si la cláusula arbitral es válida entre las partes que la han pactado desde el punto de vista formal y sustantivo, habrá que comprobar la eficacia de la institución de fondo por virtud de la cual se pretende extender los efectos de la cláusula arbitral a la sociedad no firmante" 94 , más allá de la existencia de una comunicación escrita por parte del tercero.

Si bien nos parece que esta interpretación puede ajustarse más a la realidad, ello siempre deberá analizarse desde un criterio restrictivo y que asegure el debido resguardo de las garantías de las partes. Esto último, como venimos explicando, será una cuestión de fondo que deberá ser resuelta por el juez en atención a los supuestos fácticos que hemos explicado aquí.

\section{6) BibliografíA}

Aguilar Grieder, Hilda (2001). La extensión de la cláusula arbitral a los componentes de un grupo de sociedades en el arbitraje comercial internacional, Santiago de Compostela: Universidad de Santiago de Comopstela.

Aguilar Grieder, Hilda (2009). “Arbitraje Comercial Internacional y Grupos de Sociedades" en Cuadernos de Derecho Transnacional, Vol. 1, No 2, pp. 5-29.

Arrubla Paucar, Jaime Alberto (2010). "El levantamiento del velo corporativo en Colombia” en LEón Robayo, Edgar Iván; Rincón CÁrdenas, Erick y López Castro, Yira (editores): Levantamiento del velo corporativo. Panorama y perspectivas. El caso colombiano, Bogotá: Editorial Universidad del Rosario, pp. 59-78.

Aylwin Azócar, Patricio (2005). El Juicio Arbitral, $5^{\mathrm{a}}$ ed., Santiago: Editorial Jurídica de Chile.

Aylwin Chiorrini, Andrés y Rojas Miño, Irene (2005). "Los Grupos de Empresas y sus efectos jurídico laborales en el Derecho Comparado" en Ius et Praxis, Vol. 11, No 2, pp. 197-225.

Bernardo San José, Alicia (2002). Arbitraje y jurisdicción, incompatibilidad y vías de exclusión, Granada: Editorial Comares.

$94 \quad$ Aguilar (2001) 346. 
Bernal-Fandiño, Mariana y Rojas-Quiñones, Sergio (2010). "La vinculatoriedad de un laudo arbitral frente a terceros en la doctrina del collateral estoppel'. Revista Colombiana de Derecho Internacional, no 16 , pp. 455-488.

Blackaby, Nigel y Partasides, Constantine (2015). Redfern and Hunter on International Arbitration, 6ta ed., Oxford: Oxford University Press.

Borda, Alejandro (2010). "La teoría de los actos propios. Un análisis desde la doctrina argentina”, en Corral Talciani, Hernán (edit.), Venire contra factum propium, Cuadernos de Extensión Jurídica No 18, Santiago: Universidad de los Andes, pp. 35-55.

Brinsmead, Simon (2007). Extending the application of an arbitration clause to third-party non-signatories: which law should apply?, working papers series, Social Science Research Network, disponible en http:// ssrn.. com/abstract=980483 [fecha de visita: 18 de septiembre de 2012].

Carnelutti, Francisco (1944). Sistema de Derecho Procesal Civil. I introdcción y función del proceso civil, Buenos Aires: Uteha Argentina.

Carreta Muñoz, Francesco (2008). "Deberes procesales de las partes en el proceso civil chileno: referencia a la buena fe procesal y al deber de coherencia”. Revista Chilena de Derecho (Valdivia), Vol. 21 No 1, pp. $101-127$.

Caivano, Roque (2006), "Arbitraje y grupos de sociedades. Extensión de los efectos de un acuerdo arbitral a quien no ha sido signatario". Lima Arbitration. Revista del Círculo Peruano de Arbitraje, No1, pp. $121-162$.

Contardo González, Juan Ignacio (2010). "La doctrina de los actos propios en la jurisprudencia civil chilena", en Corral TAlCiani, Hernán (edit.), Venire contra factum propium, Cuadernos de Extensión Jurídica No 18, Santiago: Universidad de los Andes, pp. 81-102.

Corral Talciani, Hernán (2010). “La raíz histórica del adagio 'venire contra factum propium non valet', en Corral Talciani, Hernán (edit.), Venire contra factum propium, Cuadernos de Extensión Jurídica No 18, Santiago: Universidad de los Andes, pp. 19-33.

Courtney, Tae (2009). "Binding non-signatories to international arbitration agreements: raising fundamental concerns in the United States and abroad" en Richmond Journal of Global Law \& Business, Vol. 8, issue 4, pp. 581-594.

De NadAl, Elisabeth y SÁnchez, Víctor Manuel (2011). "La extensión a terceros no firmantes de los efectos del convenio arbitral. La aproximación de España” en Soto Coaguila, Carlos Alberto (Dir.), Tratado de Derecho Arbitral. El Convenio Arbitral, Bogotá: Grupo Editorial Ibañez, T. I, pp. 689-704. 
Díaz-Candia, Hernando (2012) "Extensión intersubjetiva del acuerdo de arbitraje de Estado" en Sото Coaguila, Carlos Alberto (Dir.) Aplicación del convenio arbitral a partes no signatarias. Intervención de terceros en el arbitraje, Lima: Instituto Peruano de Arbitraje, pp. 161-174.

Ekdahl Escobar, María Fernanda (1989). La doctrina de los actos propios, Santiago: Editorial Jurídica de Chile.

Figueroa Valdés, Juan Eduardo (2007). "Tópicos de la Ley No 19.971, sobre arbitraje comercial internacional”, en Picand Albónico, Eduardo (coord.), Estudios de Arbitraje, Santiago: Editorial Jurídica de Chile, pp. 391-409.

García-Bolivar, Omar (2007). "El desconocimiento de la personalidad jurídica en el arbitraje internacional de inversiones" en Revista Internacional de Arbitraje, enero-junio, pp. 113-145.

Graham, James (2008). "La 'falsa' extensión del acuerdo arbitral a terceros: El ejemplo de México" en Revista Peruana de Arbitraje, No 7, pp. 173-187.

Hanotiau, Bernard y Stein, Erica (2012). "La extensión de los efectos del convenio arbitral a no signatarios: ¿Una marginalización del consentimiento?” en Soto Coaguila, Carlos Alberto (Dir.) Aplicación del convenio arbitral a partes no signatarias. Intervención de terceros en el arbitraje, Lima: Instituto Peruano de Arbitraje, pp. 57-67.

Hernández Botero, Héctor (2011). "La autonomía de la cláusula arbitral en el arbitraje comercial internacional: reflexiones y problemáticas de la experiencia colombiana” en Soto Coaguila, Carlos Alberto (Dir.), Tratado de Derecho Arbitral. El Convenio Arbitral, Bogotá: Grupo Editorial Ibáñez, T. I, pp. 401-415.

Hur, Alexandra Anne (2007). "Equitable Estoppel and the Compulsion of Arbitration" en Vanderbilt Law Review, Vol. 60, No 2, pp. 711744.

Jequier Lehuedé, Eduardo (2011), "El arbitraje forzoso. Un examen de constitucionalidad en el ordenamiento jurídico chileno", en Revista de Estudios Constitucionales, Año 9, $\mathrm{N}^{\circ} 2$ 2, pp. 453-498

Jequier Lehuedé, Eduardo (2015). Grupos empresariales. Notas sobre la responsabilidad del administrador de hecho en el derecho chileno, Santiago: LegalPublishing.

Juppet Ewing, María Fernanda (2011). "Algunas consideraciones acerca de la responsabilidad de las personas jurídicas y de los agentes que las dirigen" en Revista Actualidad Jurídica, No 24, Año XII, pp. 209226.

KryvoI, Yaraslau (2011). "Piercing the corporate veil in international arbitration" en Global Business Law Review, Vol. 1, pp. 169-186. 
Larrea A., Ana María (2010). "Comparecencia de Terceros en un Proceso Arbitral", en Revista Juridica. Facultad de Jurisprudencia y ciencias sociales y políticas de la Universidad Católica de Santiago de Guayaquil, vol. 28, pp. 35-47.

López Mesa, Marcelo (2009). "La doctrina de los actos propios: Esencia y requisitos de aplicación”. Vniversitas, No 119 jul./dic., pp. 189-222.

Lyon Puelma, Alberto (2010). "Crítica a la doctrina del acto propio: ¿Sanción de la incoherencia o del dolo o la mala fe?” en Corral Talciani, Hernán (edit.), Venire contra factum propium, Cuadernos de Extensión Jurídica No 18, Santiago: Universidad de los Andes, pp. 59-68.

Medina Garnes, Fabiola y Fermín Cabral, Manuel (2012). "Extensión del convenio arbitral a partes no signatarias y la intervención de terceros en el arbitraje" en Soto Coaguila, Carlos Alberto (Dir.) Aplicación del convenio arbitral a partes no signatarias. Intervención de terceros en el arbitraje, Lima: Instituto Peruano de Arbitraje, pp. 85-96.

Mereminskaya, Elina (2012). "Aplicación de un acuerdo arbitral a un tercero no signatario en el derecho chileno: Realidad y perspectivas" en Estudios de Derecho Comercial. III Jornadas chilenas de Derecho Comercial, Facultad de Derecho Universidad de Chile, pp. 347-355.

Merino Merchán, José y Chillón Medina, José (2014). Tratado de Derecho Arbitral, 4a edición, Pamplona: Editorial Aranzadi.

Minorini Lima, Ignacio J. (2011). "La autonomía del acuerdo de arbitraje en el derecho argentino" en Sото Coaguila, Carlos Alberto (Dir.), Tratado de Derecho Arbitral. El Convenio Arbitral, Bogotá: Grupo Editorial Ibáñez, T. I, pp. 189-198.

Müller, Thomas (2009). "Extension of arbitration agreements to third parties under Swiss law" en PLC Cross-border Arbitration Handbook, disponible en www.practicallaw.com/9-385-8457, visitado por última vez el 11 de mayo de 2012.

Orrego Vicuña, Francisco (2011). "La extensión de la cláusula de arbitraje a terceros: Realidades económicas y ficciones jurídicas" en Soto Coaguila, Carlos Alberto (Dir.), Tratado de Derecho Arbitral. El Convenio Arbitral, Bogotá: Grupo Editorial Ibáńez, T. I, pp. 363-383.

PARK, William (2009). "Non-Signatories and international contracts: an arbitrator's dilemma”, en Permanent Court of Arbitration (Ed.), Multiple party actions in International Arbitration, Oxford, disponible en http://www.arbitration-icca.org/media/0/12571271340940/park_ joining_non-signatories.pdf, [fecha de visita: 26 de junio de 2012].

Romero Seguel, Alejandro (2011). Curso de Derecho Procesal Civil, tomo III, Santiago: Editorial Jurídica de Chile.

Romero Seguel, Alejandro (2012). "La extensión del convenio arbitral a partes no signatarias: límites y posibilidades en Chile" en Sото 
Conguila, Carlos Alberto (Dir.) Aplicación del convenio arbitral a partes no signatarias. Intervención de terceros en el arbitraje, Lima: Instituto Peruano de Arbitraje, pp. 3-14.

Romero Seguel, Alejandro y Díaz Villalobos, José Ignacio (2016). El arbitraje interno y comercial internacional, Segunda Edición, Santiago: Ediciones UC.

Rosende Villar, Cecilia (2002). La Eficacia Frente a Terceros de las Sentencias Contencioso-Administrativas, Navarra: Aranzadi.

Seijas Rengifo, Teresa de Jesús (2007). "The Disregard of the legal entity" en Revista de Derecho y Ciencia Política, UNMSM, Vol. 64 (No 1 - No 2), pp. 397-426.

SuÁrez Anzorena, C. Ignacio (2005). "Algunas notas sobre los grupos de sociedades y los alcances del acuerdo arbitral según la práctica internacional", en Revista Internacional de Arbitraje, enero-junio, pp. $55-75$.

TANG, Edward Ho-ming (2009). Methods to extend the scope of an arbitration agreement to third party non-signatories, Run Run Shaw Library, City University of Hong Kong, disponible en http://lbms03. cityu.edu.hk/oaps/slw2009-4635-thm665.pdf [fecha de visita: 18 de septiembre de 2012].

Urbina Molfino, Ignacio (2011). "Levantamiento del Velo Corporativo. Sentencia de la Corte Suprema de 2 de junio de 2009". Revista Chilena de Derecho, Vol. 38 No 1, pp. 163-171.

VÁsquez Palma, María Fernanda (2009). Arbitraje en Chile, análisis crítico de su normativa y jurisprudencia, Santiago: LegalPublishing.

VÁsquez Palma, María Fernanda (2011). "Recepción del Arbitraje Comercial Internacional en Chile desde una óptica jurisprudencial. Una revisión ineludible" en Revista Chilena de Derecho, Vol. 38, no 2, pp. 349-370.

VÁsquez Palma, María Fernanda (2015). "Ley chilena de arbitraje comercial internacional: Análisis de las doctrinas jurisprudenciales, a diez años de su vigencia” en Revista Ius et Praxis, Año 21, $\mathrm{N}^{\circ}$ 2, pp. 523-552. 